\title{
RESISTING THE NUDGE
}

\author{
A Dissertation \\ presented to
}

the Faculty of the Graduate School

at the University of Missouri

In Partial Fulfillment

of the Requirements for the Degree

Doctor of Philosophy

by

PAUL HAMILTON

Dr. Paul Weirich, Dissertation Supervisor

MAY 2018 
The undersigned, appointed by the dean of the Graduate School, have examined the dissertation entitled

\section{RESISTING THE NUDGE}

presented by Paul Hamilton,

a candidate for the degree of doctor of philosophy, and hereby certify that, in their opinion, it is worthy of acceptance.

Dr. Paul Weirich

Dr. Andre Ariew

Dr. Andrew Melnyk

Thomas Lambert 


\section{Acknowledgments}

I would like to thank William Wilkerson, Nicholaos Jones, and Andrew Cling for getting me into graduate school and giving me the advice to survive it, Bill Glod for igniting my interest in the topic of this dissertation, and Paul Weirich, Andre Ariew, Andrew Melnyk, and Thom Lambert for allowing me to explore my interests and getting me through graduate school.

I would also like to thank the truck I crashed into on my way to take the LSAT. Without it, I may have ended up in law school and things would be very different. 


\section{Table of Contents}

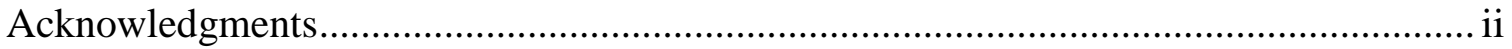

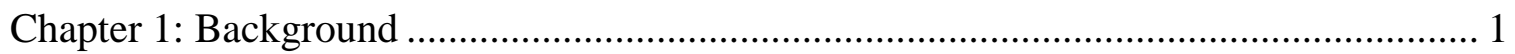

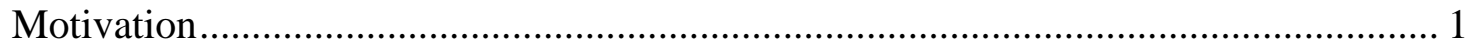

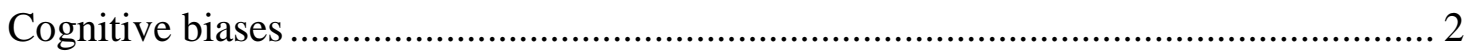

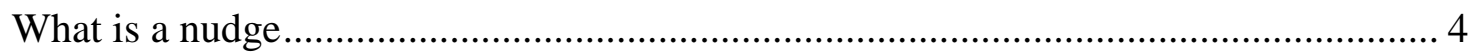

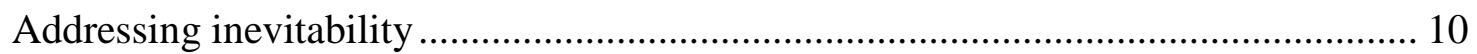

Chapter 2: Delimiting Nudges: A republican approach............................................... 20

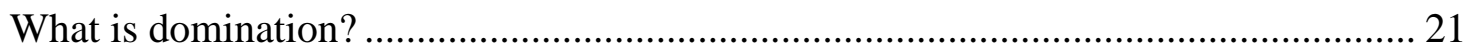

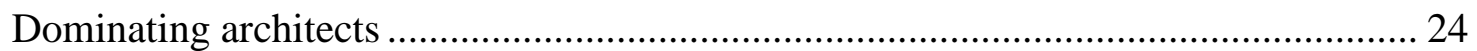

Objection - Boosting to make an effective constraint on evaluators......................... 37

Objection - Choice architects are bound by a standard ....................................... 38

Chapter 3: Nudging Is an Achievement That Threatens Other Achievements ................ 42

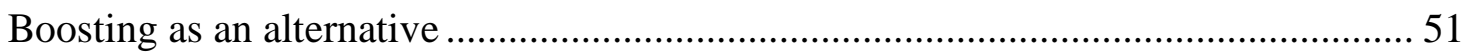

Objection - Nudge to make things more difficult or require greater exercise of

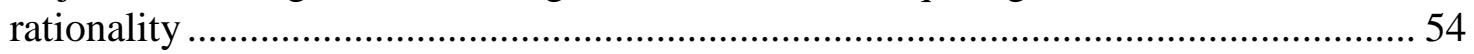

Objection - Nudging now allows for more achievements later ............................... 55

Objection - Designing a nudge is an achievement ........................................... 56

Objection - Implausibly few achievements ................................................. 57

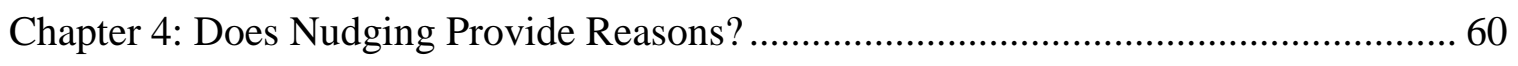

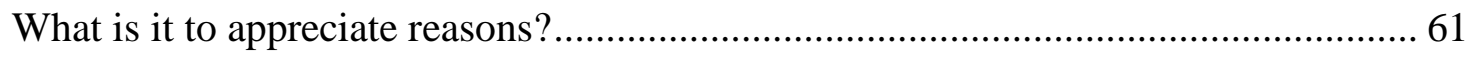

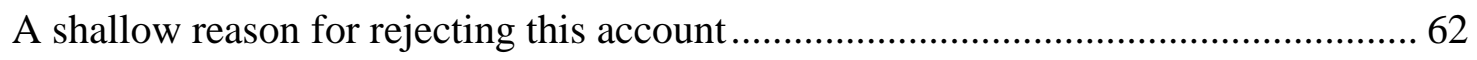

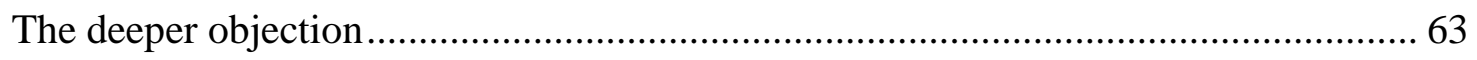

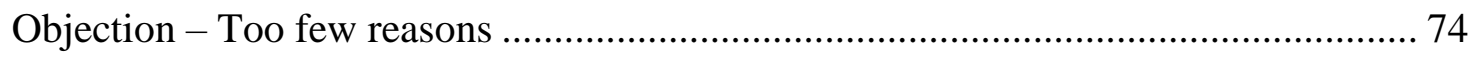

Objection - Permissible to treat people in the objective mode................................. 78

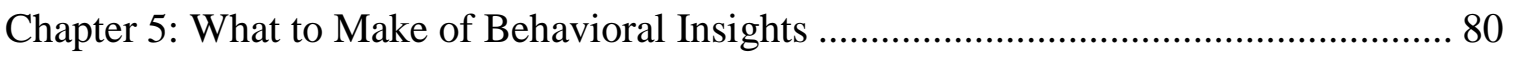

Overcoming the Presumption Against the Use of Nudges ....................................... 83

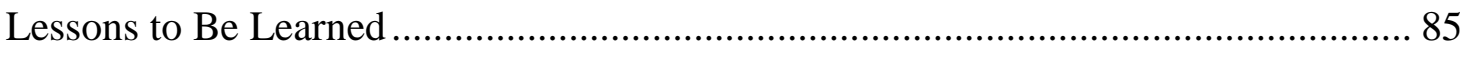

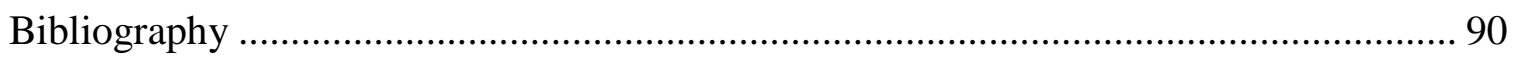

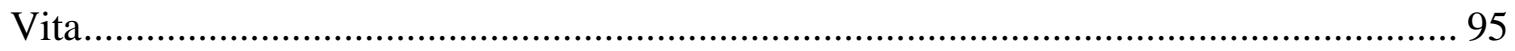




\section{Chapter 1: Background}

\section{Motivation}

Behavioral scientists have discovered that people predictably behave in ways unlike perfectly rational agents or utility maximizers. For example, it has been found that when people make choices, the degree to which they best pursue their own welfare or conception of the good is often influenced by the circumstances surrounding that choice. Cass Sunstein, Richard Thaler, and many others have proposed that these circumstances be consciously shaped to take advantage of these predictable patterns of behavior to get people to make choices that are best for the chooser. Put otherwise, many have suggested that choosers be "nudged" into making better choices.

Perhaps more importantly, governments have made policy in line with these proposals. Most notably the US and the UK have attempted to incorporate these findings of behavioral economics by creating what are popularly known as "Nudge Units". The UK's unit (the Behavioral Insights Team) has been credited with "getting the unemployed back into work faster, helping smokers give up tobacco, and motivating procrastinators to be more punctual in paying their taxes". ${ }^{2}$

Many are uncomfortable with the use of nudges. Detractors describe their use as manipulative, paternalistic, or violations of autonomy or self-authorship. I share many of these concerns. In this dissertation, I look to raise two new ways of objecting to the use of nudges. The chapters will proceed as follows. In this chapter, I clarify what counts as a nudge and respond to the objection that nudging is inevitable. In the next chapter, I argue

\footnotetext{
${ }^{1}$ I suspect that some programs proposed by these nudge units are better characterized as mistaken nudges. However, I will not explore that in detail here.

${ }^{2}$ Nesterak, Max. "Nudging the UK: A Conversation with David Halpern". Retrieved from http://thepsychreport.com/conversations/nudging-the-uk-a-conversation-with-david-halpern/
} 
on republican grounds that the use of nudges places choice architects in a position of domination over choosers. In case some degree of domination is permissible, I will also explore what elements would distinguish permissible from impermissible nudges on republican grounds. In chapter $3, \mathrm{I}$ argue that nudges can threaten the status of our actions from qualifying as achievements; and for those that still qualify, the use of nudges can make them less valuable as achievements. In the penultimate chapter, I respond to a particular defense of the use of nudges: nudges are permissible because they help one to appreciate the reasons that one has. To respond to this defense, I adopt a contemporary account of reasons to show that one either does not have reason to do what one is nudged into doing or the nudge is causally redundant in helping one to appreciate reasons. I conclude by considering how the insights that motivate the nudge project can be permissibly used.

\section{Cognitive biases}

Findings in behavioral economics reveal that we likely do not behave like the perfectly rational utility maximizers often described in economics. Rather than act like these beings, which are dubbed "Econs", we behave like "Humans". That is, we display what those in the heuristics and biases research program call "cognitive biases". ${ }^{3}$ A bias here is a deviation between the way Humans predictably act and the ways that Econs would act. To illustrate, consider the following example.

Medical Procedure: "When people are told, 'Of those who undergo this procedure, 90 percent are still alive after five years,' they are far more likely to

\footnotetext{
${ }^{3}$ I borrow the division between the heuristics and biases research program and the simple heuristics program from Grüne-Yanoff and Hertwig (2015). Thaler and Sunstein also reference the heuristics and biases approach when introducing various cognitive biases (2008, p. 23). I will briefly discuss the differences between the two programs later in this chapter.
} 
agree to the procedure than when they are told, 'Of those who undergo this procedure, 10 percent are dead after five years" " 4

The two wordings are assumed to be equivalent. ${ }^{5}$ Granting this assumption, it can be concluded that Econs would be unaffected by the wording used in describing the risks of the procedure. Put another way, no matter which wording is used, any Econ that would have had the procedure given knowledge of the risks would still elect to have the procedure and any Econ that would not have had the procedure given knowledge of the risks would still elect to not have the procedure. However, things are different with Humans. If we imagine a group of Humans who are told "Of those who undergo this procedure, 10 percent are dead after five years", a significant number of the members of that group would elect not to have the procedure but would have had it had they received the other, more positive, framing. This predictable deviation from how Econs would act marks a cognitive bias $^{6}$. There are many such biases, but I would like to highlight a few prominent ones.

Framing: This is the bias at work in the example above. The way options are presented can impact the choices that are made. In Medical Procedure, the risks of the procedure are framed in terms of the percent of patients who have died or the percent who are still alive five years after having the procedure.

Anchoring: In cases of anchoring, choosers must select a definite value from a spectrum of options and they are influenced by the initial value they are exposed to. For example, when negotiating over the price of an item, the initial offer (from the buyer or the seller) has a disproportionate impact on the final price. A high

\footnotetext{
${ }^{4}$ Sunstein and Thaler (2003). p. 1161

${ }^{5}$ There is some disagreement over what occurs in framing and default cases. One possibility is that framings and default rules are interpreted as implicit endorsements. In some of the literature, this is described as information leakage. One paper that explores information leakage when logically equivalent frames are used is Sher and McKenzie (2006). For now, I will grant that there is no information leakage.

${ }^{6}$ From the literature I have looked at, it is difficult to say who has the bias. One option would be to say that the people who alter their behavior because of the wording used are the ones with a bias but those whose behavior doesn't change do not have a bias. But, an alternative interpretation might be that each person has the bias and is impacted by which wording is used, but for some individuals the impact of the bias is not large enough to make them adjust behavior as a result of the wording used.
} 
initial offer tends to lead to a higher final price and a lower initial offer tends to lead to a lower final price.

Default Bias/Status Quo Bias/Inertia 7 : Here I am grouping two similar biases, the default bias and the status quo bias (also known as inertia). When individuals make choices, they disproportionately stick with the default option. For example, think back to the last time you installed a piece of software. You likely kept the default options and installation setup. Individuals also tend to maintain their current state of affairs. For example, after installing some software, you likely kept whatever setting you selected during installation.

Loss Aversion: This bias identifies the phenomenon where individuals are more likely to avoid a perceived loss than pursue a perceived gain of equal value. For example, more people can be expected to do some action to avoid a surcharge than would be expected to do some action to receive a discount of equal value, even if either action will result in the same final price. The reason for this is that individuals perceive a surcharge as a loss, but perceive a discount as a gain.

Social Norming: Stephen Dubner dubbed social norming "essentially academicspeak for peer pressure". ${ }^{8}$ Individuals are more likely to do some act when it is presented as something that others like them already do.

\section{What is a nudge}

These biases are important because they impact the choices we make. Choices are made within a context that includes elements like the methods used in selecting or presenting options. For example, how options are framed or which option is the default option is part of a given choice context. At least some parts of a choice context can be intentionally designed, and when they are the designer is known as a choice architect.

Sunstein, Thaler, and others have argued that choice architects should use the biases of choosers to promote the welfare of those choosers by manipulating the context in which choices are made. For example, in Medical Procedure, if it is believed that

\footnotetext{
${ }^{7}$ Given that the status quo seems to be a kind of default option, it seems appropriate to group the two.

8 "Freakonomics" "The Maddest Men of All" transcript available at http://freakonomics.com/2015/02/26/the-maddest-men-of-all-full-transcript/
} 
having the procedure generally promotes the welfare of patients, then, they might argue, there should be a policy that instructs doctors to frame the risks of the procedure in terms of how many patients survive and not in terms of how many die. The goal of such a policy would be to have more patients have the procedure than otherwise would.

Specifically, Sunstein and Thaler would advocate that the policy be designed to "nudge" the chooser into making a particular choice. Economists, philosophers, and policy makers have noticed the potential that nudging can have. For example, it has been suggested that nudging can be used by doctors to paternalistically promote wellbeing without infringing on patient autonomy. ${ }^{9}$

However, for all of the excitement surrounding the potential of nudging, it is somewhat unclear how to define "nudge". Many have noted that there seems to be confusion or unclarity surrounding the term. As an illustration of this confusion, consider that a House of Lords report on the use of nudges states that

We received differing accounts of the Government's use of "nudge". For example, the Sustainable Transport White Paper contrasts "nudging" with anything that forbids or restricts choice, and Norman Baker MP, Parliamentary Under Secretary of State for Transport, equated "nudging" with a broad range of non-regulatory interventions, such as the provision of bus and train timetables. Mr. Lewin, however, suggested that "nudging" had to involve "prompted choice" and therefore excluded informational and promotional forms of non-regulatory intervention. ${ }^{10}$

Fueling such confusion may be that Thaler and Sunstein seem to provide at least two non-equivalent definitions of the term, and it can be difficult to see how some of the examples they cite qualify under either. For the remainder of this section, I will try to take on the challenge of finding a definition that best accomplishes three goals: i) it

\footnotetext{
${ }^{9}$ For example, see Cohen (2013).

${ }^{10}$ Parliament (2011, p. 12).
} 
connects what counts as a nudge to the findings in behavioral economics that supposedly justify nudging, ii) it captures some of Thaler and Sunstein's examples, and iii) it reflects the paternalistic commitments found in Sunstein and Thaler's work on nudges.

The most common way to define a nudge is as "any aspect of the choice architecture that alters people's behavior in a predictable way without forbidding any options or significantly changing their economic incentives". ${ }^{11}$ Returning to Medical Procedure, by this definition, if the positive framing is used to influence patients into having the procedure, then the frame counts as a nudge. Patients have not been barred or economically disincentivized from opting to not have the procedure and there is a predictable effect from selecting that choice architecture.

But, it seems implausible to describe some things as being nudges that satisfy this definition. For example, imagine that I am giving my students a multiple-choice exam and, after handing out the exam, I tell them that B is the correct answer to question 3. My providing this information is part of the context in which my students choose what they believe to be the correct answer, and so this information is part of the choice architecture. One hopes that this intervention will alter the behavior of some of my students in a predictable way. Further, I have altered their behavior without forbidding any choices or significantly changing their economic incentives. So, on this definition of a nudge, I have nudged them. But, this seems counterintuitive. Providing someone with information or rationally persuading someone doesn't seem like a nudge. After all, when providing information or rationally persuading, we generally do not appeal to the biases that other

\footnotetext{
11 Thaler and Sunstein (2009, p. 6).
} 
parties might have. These actions seem disconnected from the behavioral economics that inspires the nudge literature.

A potential second definition that Thaler and Sunstein provide is that "a nudge is any factor that significantly alters the behavior of Humans, even though it would be ignored by Econs". ${ }^{12}$ On this definition, my telling my students the answer to question 3 should no longer count as a nudge. Econs should not be expected to ignore new or helpful information. Further, this definition also excludes most rational persuasion from counting as a nudge. Finally, this definition clearly connects with the behavioral findings that inspire and supposedly justify nudging.

However, this definition is not perfect. It states that Econs would ignore a nudge, however, many of the examples of nudges that Sunstein and Thaler provide would not be ignored by Econs. ${ }^{13}$ For example, a program that Sunstein and Thaler mention in their chapter "A Dozen Nudges" looks to reduce teenage secondary pregnancy. The program works by giving teenage mothers a dollar for each day they are not pregnant. It is claimed that this program is effective because "the small recurring payment is salient enough to encourage teenage mothers to take steps to avoid getting pregnant again". ${ }^{14}$ The problem is that Econs would not ignore this program since the additional income would be expected to shape the decisions of some perfectly rational actors. We would expect there to be some marginal cases where forgoing this additional income tips the scales such that

\footnotetext{
12 They do not present it as an alternative definition. Instead, they treat it like an implication of their definition. Thaler and Sunstein $(2009$, p. 8).

${ }^{13}$ Hausman and Welch (2010) make this objection in relation to the Toxic Release Inventory and other examples. Selinger and Whyte make a distinction between nudges, mistaken nudges, and fuzzy nudges as a way to categorize examples where there is no change in economic incentives and people respond because of cognitive biases, the intervention succeeds because of a change in economic incentives, and examples where it is not clear if the intervention succeeds because of biases or a change in incentives.

${ }^{14}$ Thaler and Sunstein (2009, p. 236).
} 
the opportunity cost of having a second child is too high. While this second definition of a nudge makes the findings in behavioral economics clearly relevant, it would leave many of Sunstein and Thaler's examples of nudges as non-nudges.

It also is not clear if this example counts as a nudge according to the first definition. For some of us, a dollar a day seems to be a significant financial incentive. However, as Hansen points out in his "The Definition of Nudge and Libertarian Paternalism" "15, what it means for something to significantly change economic incentives is unclear. Hansen's way of understanding what a significant change would be nicely respects the behavioral economics' foundations of nudging. A change in the choice architecture that seems to change incentives significantly does so when the effect on behavior is disproportionately large. That is, when the behavior change is larger than the expected change were those choosers Econs. So, if more mothers avoid secondary pregnancy than could be plausibly predicted if one assumed that the mothers were Econs, then the payment of a dollar a day is a significant change in economic incentives. ${ }^{16}$

Adding to the confusion is that Thaler and Sunstein also discuss what they call "libertarian paternalism" in a way that makes it unclear if it is a separate concept or a third possible way to define what a nudge is. As Thaler tells it, the idea for libertarian paternalism came first. He and Sunstein were looking for a title for their book when an editor "suggested that the word "nudge" seemed to capture what we were trying to do". 17

As they define it, libertarian paternalism is a form of soft paternalism where those shaping choice contexts intentionally try "to steer people's choices in directions that will

\footnotetext{
${ }^{15}$ Hansen (2015).

${ }^{16}$ Hansen (2015, p. 11).

17 Thaler (2016).
} 
improve their lives" without forbidding any options. ${ }^{18}$ It is libertarian in that choosers are not denied options, but it is paternalistic in that "choice architects are not merely trying to track or implement people's anticipated choices. Rather they are self-consciously attempting to move people in directions that will make their lives better. They nudge. ${ }^{19},{ }^{20}$

So, nudging and libertarian paternalism seem to be very similar ideas. However, we cannot use the definition of libertarian paternalism to define what a nudge is. This is because when Thaler signs copies of Nudge, he adds "nudge for good". ${ }^{21} \mathrm{He}$ seems to leave it open that evil nudges are possible. Since libertarian paternalist interventions have to be intended to make people's lives better, they would be incompatible with nudges that are intended for anything other than the good.

Because it is not clear that Sunstein and Thaler have a single, clear definition of nudge, I will use a modification of Hansen's definition. He concludes that a nudge is "a function of (I) any [intentional] attempt at influencing people's judgement, choice, or behavior in a predictable way, that is (1) made possible because of cognitive boundaries, biases, routines, and habits in individual and social decision-making posing barriers for people to perform rationally in their own self-declared interest, and which (2) works by making use of those boundaries, biases, routines, and habits as integral parts of such attempts. Thus a nudge amongst other things works independently of: (i) forbidding or

\footnotetext{
${ }^{18}$ Thaler and Sunstein (2009, p. 5).

${ }^{19}$ Thaler and Sunstein (2009, p. 6).

${ }^{20}$ In their 2003 paper, "Libertarian Paternalism is not an Oxymoron", Sunstein and Thaler say that "private and public planners are not trying to track people's anticipated choices, but are self-consciously attempting to move people in welfare-promoting directions" (p. 1162). The 2008 addition of the word "merely" seems to imply that architects are trying to track such things to some degree, however, this does not seem to be reflected elsewhere. I do not think that the addition of "merely" was a substantive change and I will ignore what it may imply.

${ }^{21}$ Thaler (2016).
} 
adding any rationally relevant choice options, (ii) changing incentives, whether regarded in terms of time, trouble, social sanctions, economic, and so forth, or (iii) the provision of factual information and rational arguments". ${ }^{22}$

Hansen's definition has the virtue of connecting what counts as a nudge to the findings in behavioral economics that supposedly justify nudging, and it clarifies how some problematic examples can still qualify as nudges. But, it does not reflect the paternalistic commitments of Sunstein and Thaler. Hansen argues that "nudge" and "libertarian paternalism" should be separate concepts. However, since I am interested in the permissibility of nudging, I will assume that nudges have to conform to the principles of libertarian paternalism to qualify as nudges. That is, to qualify as a nudge, an action must have been done with the intent of improving choosers' lives without trying to anticipate their choices. Placing this constraint on what counts as a nudge may not produce the best definition of a nudge, but it produces a charitable definition given that I will argue that nudges are impermissible.

\section{Addressing inevitability}

A common objection raised against any anti-nudge position is the inevitability objection. Thaler and Sunstein claim the "antinudge position is unhelpful—a literal nonstarter" because the presence of choice architecture is inevitable, so choices will be shaped in some way. ${ }^{23}$

However, this is not sufficient for showing that nudging is inevitable. It may simply show that influence is inevitable given that people have these biases. After all,

\footnotetext{
${ }^{22}$ Hansen (2016, p. 20).

23 Thaler and Sunstein (2009, p. 11).
} 
nudges are often contrasted with mandates and bans, and that contrast implies that these are alternatives. ${ }^{24}$ One could even imagine a world where there is no subset of nudges that are inevitable because some hard paternalist dictates all actions. So, one cannot assume that even some subset of nudges is inevitable.

A second reason to reject that nudging is inevitable is that, as I have defined it, nudging requires that one intend to influence the behavior of another. But choice architects do not have to have this intention when constructing a choice architecture. For example, when setting up a display of goods, the choice architect does not have to intend to nudge choosers toward buying a particular good; the architect can merely intend to display his or her goods. Or, when setting up an employee retirement program, the architect may simply try to approximate the industry standard.

Of course, it would be difficult for me to argue that nudging is wrong because it gives too much power to others or threatens our doing things for ourselves and respond to the inevitability objection by appealing to the use of mandates and bans. It seems that those would be even greater threats. It is also difficult to ask choice architects to ignore findings about how choosers think. The genie is out of the bottle. Thankfully, in at least some cases, there is an alternative that is compatible with the arguments that I will give later: boosting.

Boosts are used to increase the competence of decision makers. ${ }^{25}$ This can be done by changing the environment or by increasing the decision-making ability of choosers by increasing their set of skills, strategies, or knowledge. ${ }^{26}$ For example, risks

\footnotetext{
${ }^{24}$ See Thaler and Sunstein (2009, p. 10) and Cass Sunstein's appearance on Conversations With Tyler (Cowen 2016).

${ }^{25}$ Grüne-Yanoff and Hertwig (2016, p. 152).

${ }^{26}$ Grüne-Yanoff and Hertwig (2016, p. 156).
} 
can be presented in terms of absolute risk reduction as opposed to relative risk reduction to help people avoid mistakes in understanding risks. Or, information can be presented as natural frequencies as opposed to probabilities or percentages. Finally, individuals can be taught or provided with strategies that help them better make decisions such as fast-andfrugal-trees or ways of translating complex statistical information into a more understandable form.

There are three points I want to make in favor of boosting as an alternative to nudging. First, when a boost takes the form of the provision of a strategy, it usually imparts a skill that is generalizable. For example, the strategy of converting probabilities into natural frequencies in order to avoid the influence of framing and the base-rate fallacy is a generalizable strategy. It comes at the cost of an initial investment in education and requires the chooser to have sufficient motivation to learn and use this skill, but it is effective at improving decision maker competence. This contrasts with the use of a nudge, which can only have an influence in a particular instance of choice architecture.

The second point in favor of boosting is that boosting does not require an assumption about the chooser's values or welfare. Nudges that are used with an intent to improve the welfare of choosers face a knowledge problem. To succeed in improving the welfare of choosers, nudgers have to know what choosers value, which may be difficult or impossible to know. Boosts are used with the intent of improving the competence of choosers. They are not used with the intent of directing choosers toward a particular selection. For this reason, those boosting choosers do not have to make assumptions about, nor try to get knowledge of, the values of choosers. For example, a doctor 
employing a nudge has to make assumptions about a patient's medical values such as the tradeoffs of risk, fullness of recovery, recovery time, etc. as well as his or her nonmedical values such as financial cost, cost of lost time with family, value of current habits and routines, etc. A doctor employing a boost is not burdened with the need of knowing a patient's values, but tries to present information such that the patient has an accurate understanding of medical options and risks. This allows the patient to use this knowledge, along with knowledge of his or her values, to make a decision.

Thirdly, Sunstein should be in favor of boosting as a desirable alternative to nudging. I am not implying that all advocates of nudging or libertarian paternalism should be in favor of boosting over nudging nor that they are committed to approving of boosting. But, nudging's main advocate should be in in favor of it.

There are two reasons that Sunstein should think that boosting is superior. First, he and Thaler identify biases as things that often cause choosers to do things detrimental to themselves. Because boosts are generalizable, they help to reduce the influence of these biases across cases and therefore should reduce or stop biases from causing choosers to harm themselves. Secondly, Sunstein believes that choice architects should "create a choice architecture that will make it more likely that people will promote their own ends, as they themselves understand them". ${ }^{27}$ Boosting likely does this task better than nudging because, as mentioned earlier, the choice architect does not have to assume knowledge of a chooser's values but leaves it to the chooser to decide how to proceed given his or her ends.

${ }^{27}$ Sunstein (2014, p. 19). 
One can raise two kinds of objections to my advocacy of boosting over nudging. First, as Grüne-Yanoff and Hertwig explain, nudging and boosting have emerged as two different policy recommendations from two different research programs. Nudging emerges from the heuristics and biases research program and boosting from the simple heuristics research program. Each one has a different understanding of the mechanisms that cause various decision-making errors, and they differ on the norms that should be used for evaluating human choices.

The heuristics and biases approach views decision making as systematically flawed because automatic biases produce poor decisions when compared to the standards of classic economic rationality. The decisions of Humans are different from the decisions of Econs because Humans are flawed. However, these flaws can be leveraged to guide Humans into Econ-like behavior. The simple heuristics approach views human decision making as one that utilizes heuristics to satisfice given that one lacks perfect information, faces conditions of uncertainty, and has limited computational capacity. On this view, Humans should not be held to the standards of Econs, are not fundamentally flawed, and decision-making capabilities can be improved by altering the environment to encourage understanding or by improving decision making competence. ${ }^{28}$

Given that boosting and nudging emerge from different schools of thought, one might say that presenting boosting as an alternative to nudging begs the question against nudging. It requires an assumption that the research that grounds nudging is wrong in order to generate the conclusion that there is a viable alternative to nudging.

\footnotetext{
${ }^{28}$ This very quick summary draws heavily from Grüne-Yanoff and Hertwig (2016, p. 150-152 and 164-
} 165). 
I am not in a position to argue that one research program is superior to the other. However, I do not believe that I need to. Nudging and boosting seem to be distinct kinds of actions that have distinct moral implications. And, as I am only interested in the moral implications of nudging, I am free to treat them as alternative kinds of actions and let the psychologists decide which policy is better grounded in cognitive science.

The second kind of objection notes that boosting is not without a cost. As I previously noted, boosting can require an initial investment of resources and effort on the part of the individual being boosted, particularly when he or she has to learn a new strategy. I grant this, and I will later examine when my arguments against nudging would commit me to having a concern about this additional cost. For now, I want to note two other costs that seem important.

A cost of boosting is that it may sacrifice the option value that nudging provides. As Hertwig and Ryall explain, nudging a chooser has option value because one could boost the chooser later. However, a boost may permanently keep one from being nudged in the future. That is, the boost may debias the chooser (or allow the chooser to effectively avoid bias) in future situations. In which case, the chooser could not be nudged towards making a particular selection. Advocates of nudging may find it preferable to maintain this option value in case a particular chooser will only make a particular welfare-improving selection if his or her cognitive biases are exploited.

The final cost I wish to address is a modification of an objection to nudging. The objection relies upon the theory of the second best to note that counteracting one bias might actually lead to a worse outcome. ${ }^{29}$ Biases may be structured such that some biases

${ }^{29}$ Rizzo and Whitman (2007, p. 427). They refer to it as "the second-best problem". 
mitigate or eliminate the effects of others. Noting that a chooser has a particular bias and then nudging so as to counteract that bias could lead to a worse overall outcome if all biases are not addressed.

Here is an example to illustrate how this might happen. Investors may have two counterbalancing biases. On the one hand, they may display a systematic overconfidence that sometimes causes them to make overly-risky investments. On the other hand, investors may undersave for retirement because they overly discount the future. A nudge may be designed to neutralize the overconfidence of the investors. However, this can result in a further decrease in savings as the discounting of the future now goes unchecked. As a result, investors may be worse off overall unless they are nudged to neutralize their bias to overly discount the future. ${ }^{30}$

The extent to which this objection should concern advocates of nudging likely depends on the particular nudge involved. If a nudge is used to employ a particular bias so that a particular outcome is made more likely, then one should have second best concerns only in determining if the outcome is actually made more likely. But, if people are recognized to have a particular kind of bias and therefore a particular nudge should be implemented, then there should be a second best concern. Counteracting that particular bias for the sake of mitigating the bias may reduce overall welfare as in the example above.

Applied to boosting, one may be concerned that a boost eliminates a particular bias, but since that bias may have been counteracting other biases, removal of the bias could reduce overall decision-maker competence. An objector might claim that to safely

\footnotetext{
30 This example is adapted from Rizzo and Whitman (2007, p. 427-428).
} 
eliminate a bias, one would need to eliminate all of the biases or at least know that eliminating the bias does not allow others to have a larger influence and reduce the decision-maker's competence. The cost of eliminating all biases or acquiring such knowledge might be very high, in which case, there is a very large potential cost to boosting.

I want to resist this line of thought. Boosts are not used to counteract particular biases but to increase overall competence. Boosts do not eliminate one bias and allow other biases to produce results that are overall worse since the measure of success or failure for a boost is an overall measure.

Before moving beyond the topic of boosting, I want to note that in some cases it may not be clear if a particular intervention is a boost or a nudge. For example, the Columbia Police Department is considering a change to how it acquires consent to search vehicles. ${ }^{31}$ The change would be a requirement to secure written consent before searching the vehicle. This change would count as a nudge if it were instituted with the intent of using the cognitive biases of drivers to make it salient that they may withhold consent and if the nudge is used to encourage a particular outcome (likely there being fewer cases of drivers' consenting to searches). However, if the policy is implemented without an attempt to use a particular bias or encourage a particular outcome, then it seems to be a boost. It informs drivers that they may decline having their vehicles searched when verbal requests to search can seem like orders. ${ }^{32}$

\footnotetext{
${ }^{31}$ Hough (2016).

${ }^{32}$ Hough (2016).
} 
Finally, it is important to note that I do not want to treat boosts as nudges by another name even though it may be difficult to tell if an intervention is a boost or a nudge. Some, such as Sunstein, have tried to create a category called "educative nudges". Drawing from dual process theory, Sunstein also calls these interventions "System 2 nudges". ${ }^{33}$ The general idea is that these nudges provide information that encourage deliberation and reflective thinking. For example, including nutritional information in a cafeteria would count as a System 2 nudge. And, according to Sunstein, boosts are educative/System 2 nudges by another name. ${ }^{34}$

There are two dangers in calling such interventions nudges. First, doing so would require changing the definition of "nudge". The definition of nudge is supposed to imply that Econs are immune from their influence. However, Econs are not immune to information. System 2 nudges would be expected to alter their behaviors. And, while it is possible to broaden the definition of nudge to include the provision of information, doing so disconnects nudges from the findings about cognitive biases that motivate, inform, and supposedly justify the use of nudges.

The second danger is that by labeling System 2 nudges as nudges, Sunstein is playing into Rizzo and Whitman's hands. Rizzo and Whitman draw from the slippery slope literature to show that while there might be reasonable distinctions between kinds of interventions, these distinctions might not be effective when we assume that nudgers are susceptible to biases that are conducive to creating slippery slopes ${ }^{35}$. Applying their argument here, one can note that nudgers are likely to have a bias towards simple

\footnotetext{
${ }^{33}$ Sunstein (2016a) and Sunstein (2016b).

${ }^{34}$ MizzouLaw (2016).

${ }^{35}$ Rizzo and Whitman (2007 p. 438-440).
} 
principles. To illustrate, imagine that a policy to include calorie information in a cafeteria is justified only because it is a System 2 nudge and therefore appeals to the deliberative capacities of choosers. This policy has a narrow justification. A broader justification, that all nudges are justified would have also justified this policy if it were true that all nudges are justified. Rizzo and Whitman note that an individual with a bias for simple principles might incorrectly (or opportunistically) believe that the simpler justification was the one that justified the policy and therefore incorrectly believe that other nudges are also justified. So, while the distinction between types of nudges is reasonable, it creates a concern that slippery slopes will arise because the distinction may not be effective. It seems plausible that an effective way of avoiding this instance of the slippery slope concern is to not treat System 2 nudges as a type of nudge. Rather, to the extent that there is overlap between particular System 2 nudges and boosts, one should use the term "boost". 


\section{Chapter 2: Delimiting Nudges: A republican approach}

In the previous chapter I adopted the following definition of "nudge" from Hansen: "a function of (I) any [intentional] attempt at influencing people's judgement, choice, or behavior in a predictable way, that is (1) made possible because of cognitive boundaries, biases, routines, and habits in individual and social decision-making posing barriers for people to perform rationally in their own self-declared interest, and which (2) works by making use of those boundaries, biases, routines, and habits as integral parts of such attempts. Thus a nudge amongst other things works independently of: (i) forbidding or adding any rationally relevant choice options, (ii) changing incentives, whether regarded in terms of time, trouble, social sanctions, economic and so forth, or (iii) the provision of factual information and rational arguments" ${ }^{36}$ I also said that a nudge must have been used with the intent of improving choosers' lives without trying to limit or anticipate their choices. That is, to count as a nudge, it must be libertarian paternalistic. I also responded to the inevitability objection by saying that, at least in some cases, boosts are an alternative.

In this chapter, I give a republican objection to the use of nudges. That is, I argue that the use of nudges places choice architects in a position of domination over choosers. ${ }^{37}$ I also try to argue that this counts against the use of nudges. I structure this chapter into five sections. The first section will define "domination". In the second and third sections, I give an analysis of nudging and domination. I advocate for boosting as an

\footnotetext{
${ }^{36}$ Hansen (2016, p. 20).

${ }^{37}$ Grüne-Yanoff (2012, p. 636, 638) also notes that libertarian paternalist policies enacted by a government reduce the republican liberty of its citizens.
} 
alternative and consider what the characteristics are of nudges that do not contribute to domination in the final two sections.

\section{What is domination?}

Traditionally, an individual is considered free if and only if he or she is not interfered with. This understanding of freedom seems to work fairly well. It correctly captures various cases; and in general, freedom under this definition seems to be something of value. However, the republican insight is that the definition incorrectly captures some cases where an individual does not seem to be free. For example, consider a slave with a (to this point) benevolent master. The master allows the slave to do what the slave likes. That is, the master (to this point) rarely interferes with the slave. The master could interfere and have the slave beaten, sold, or killed whenever he or she wishes, but the master has not (to this point) done so. Under the definition of freedom as noninterference, during those stretches of time where the master is not interfering, the slave is free. But, for many, it is counterintuitive to say that a slave is ever free. Defining freedom as non-interference seems to get this case wrong.

These kinds of cases may not be rare. It seems to me that people often reasonably feel unfree even when they are not being interfered with. It would be reasonable for the slave to feel this way. Similarly, it would have been reasonable for individuals to feel as though they were not free to walk around New York City when there was a concern that they may be stopped and frisked for seemingly no good reason. Workers at Wells Fargo might have felt as though they were not free to raise concerns over the practice of opening accounts without the account holders' consent because they feared being 
sanctioned even if they were not personally interfered with. For example, employees may have feared having negative remarks left on their U5s, which would make it difficult for them to find another job in banking. The capacity for Wells Fargo to harm them may have left them feeling unfree even if they were not being interfered with. ${ }^{38}$ Understanding freedom as noninterference counterintuitively labels the individuals in these cases as being free.

The alternative that republicans propose is that one is free if and only if he or she is not dominated. That is, one is free if and only if no one has the capacity to arbitrarily interfere with him or her. ${ }^{39}$ To put it more formally, I will understand an interference to be an action that an individual intentionally does that makes things worse for another. Examples of interferences include the use of restraints, threats, "the deceptive or nonrational shaping of people's beliefs or desires", making the choices available to another worse, or intentionally worsening the perception of the expected payoffs and benefits of available options. ${ }^{40}$

It is important to note that I am not requiring that the harm produced by an action be intentional for that action to count as an interference. I am only requiring that the action that produces the harm be intentional. It is difficult to tell if this is a deviation from Pettit's definition of an interference. However, to the extent that it does deviate, I think it is justifiable. Requiring that the action be intentional as opposed to requiring that the harm be intentional maintains the intuition that paternalistic acts can interfere with one's

\footnotetext{
${ }^{38}$ For more on Wells Fargo, see Planet Money's Episode 732: "Bad Form, Wells Fargo".

${ }^{39}$ Lovett (2017) and Pettit (1997, p. 52).

${ }^{40}$ Pettit (1997, p. 52-53).
} 
ability to pursue his or her own ends even though paternalistic acts are intended to improve welfare.

Of course, one's having the capacity to interfere is not the same as having the capacity to interfere arbitrarily. Sometimes one's ability to interfere with another is constrained by clear rules and procedures that are effective at constraining the power of the interfering agent. For example, we hope that the capacity of police officers to interfere with citizens is limited by various effective laws and regulations. When those regulations are effective, police officers do not stand in a position of domination over citizens. They can interfere with citizens, but not arbitrarily. And, when officers are able to act with impunity, there is understandable outrage that officers are allowed to arbitrarily interfere with citizens.

While the above example gives a sense of what "arbitrary" means, it is not a definition. As there is not a universally accepted definition, ${ }^{41}$ I propose the following one: an interference is arbitrary if and only if a) whether or not the interference occurs, or its content, is the choice of the interferer, b) the capacity to interfere is not effectively constrained by some procedure, and c) the interferer does not have to track "the shared ideas [of those subject to interference] as expressed through suitably-structured deliberative procedures". ${ }^{42}$ This definition is formed by conjoining conditions from two separate accounts of arbitrariness. So, if an interference is arbitrary under this definition, then either of the two accounts would label the action arbitrary. Applying this definition to the slave-master example, we see that the master's capacity to interfere is arbitrary

${ }^{41}$ Lovett (2017).

${ }^{42}$ Lovett (2017). 
because the master chooses whether or not any interference occurs and that choice is not constrained in either of the ways mentioned in conditions $b$ or $c$.

An important thing to note about the definition of domination that I have provided is that it treats domination as binary. One either is or is not subject to the arbitrary interference of another. It is not obvious to me that this is or is not correct the view. It seems possible that there are degrees of domination, and that the moral impermissibility of domination-producing actions may depend on the degree of domination involved. I will explore the possibility of degrees of domination later; but for the next section, I will treat domination as binary and I will assume that there is a moral side constraint against infringing the republican freedom of another.

\section{Dominating architects}

In this section I argue that, when nudging, choice architects are in a position of domination over choosers. I do so by first establishing that choice architects have power over choosers. I then show that they have the power to interfere. Finally, I argue that they have the power to interfere arbitrarily.

Recall the example of Medical Procedure from the previous chapter. There, the framing used in explaining the risks of the procedure has an impact on the decision that choosers make. That is, a choice architect's selection of one wording over another impacts the probability that a chooser will elect to have the procedure. Since an indicator that one has power over someone is that he or she can change the probability that the other person does one thing and not another, ${ }^{43}$ the example illustrates that choice

\footnotetext{
${ }^{43}$ Lovett (2001).
} 
architects have power over choosers. Choice architects exercise this power by the use of such devices as framing and the setting of defaults. If choice architects did not have power over choosers, there would be no point in consciously shaping choice contexts. The actions of choice architects would be fruitless.

Of course, it is not enough to simply note that a choice architect has power over another in order to show that he or she can interfere with that other. Recall that as defined above, an interference has to negatively impact the welfare, choice options, etc. of the individual being interfered with. If an individual's power over me is limited to doing only what makes me better off, then he or she does not have a capacity to interfere. However, choice architects do have a capacity to interfere.

To show this, let us return to Medical Procedure. Because patients can be influenced into selecting one of two nonequivalent options, they can be influenced into selecting the option that is worse for them. That is, a choice architect may decide that the framing to be used by doctors is the one that mentions how many patients are dead five years after having the procedure. This will nudge some patients into not having the procedure even though they would have had it if they had received the alternative framing. Of that group, some would have been better off had they had the procedure. Those individuals have been interfered with, in which case, the architect had the capacity to interfere. This generalizes to any cases where the nudge can influence people into one of many unequal choices as they can be influenced into making a choice that is worse for them. To further illustrate this, I want to turn to two more examples.

The first example concerns uninsured motorist policies enacted in New Jersey and Pennsylvania. In New Jersey, individuals were given the default option of a low premium 
plan that did not include a right to sue. Plans were available to motorists who wanted the right to sue at the cost of having a higher premium, but one would have to opt-into these plans. In Pennsylvania, the options were reversed. The default was that individuals would pay a higher premium but have a right to sue, but motorists could opt to give up this right in exchange for a lower premium. In New Jersey, 20 percent of motorists changed plans to acquire the right to sue. In Pennsylvania, 25 percent of motorists gave up their right to sue. What the example shows is that it matters what the default option is. If it did not matter, then one would expect each state to have the same proportion of motorists who have the right to sue and the higher premium. Instead, the setting of the default option causes some individuals who would have the right to sue had they lived in Pennsylvania to have a policy without that right because they live in New Jersey (or vice versa). ${ }^{44}$

It is reasonable to assume that some individuals living in Pennsylvania are worse off than they would have been under the New Jersey plan (or vice versa). That is, it is reasonable to assume that some individuals living in one of these states stuck with the default option but would have been better off had they been in the other state under its default plan. It is reasonable to assume this because the options are not equivalent, people disproportionately stayed with the default option, and it can be assumed that staying with one of these options cost some customers more than it otherwise would have. Those individuals have been interfered with. They are made worse off because the architect selected one default and not another.

The second example concerns retirement savings. Bubb and Pildes draw from a 2001 study by Bridgette Madrian and Dennis Shea to highlight some of the harmful

\footnotetext{
${ }^{44}$ Sunstein and Thaler (2003, p. 1176).
} 
effects of automatic enrollment retirement savings plans. According to the study, the plans were successful at increasing the initial participation rate but the low default savings rate actually reduced the overall retirement savings rate and reduced the amount employees would have for retirement. As Bubb and Pildes note, "workers [contributed] at high rates under a traditional opt-in plan but under automatic enrollment they are instead enrolled at the relatively low default contribution rate of the plan — and then stick with that default." ${ }^{\prime 4}$ So, while the savings rate for non-participants increased, the power of the default pulled down the savings rate of many employees to the low default rate. When the implementation of an automatic enrollment retirement savings plan is a nudge, it is intentional, and it non-rationally shapes the preferences of employees to save at a particular rate that overall diminishes the welfare of some employees. Given the definition above, these employees have been interfered with.

Having shown that choice architects can interfere, it now has to be shown that they stand in a position to arbitrarily interfere. Returning to our examples, it can be shown that condition $a$ for arbitrariness is satisfied. The content of the interference is subject to the judgement of the choice architect. He or she gets to decide which of the framings or defaults is used. To put it bluntly, the act of selecting a choice architecture is an act of selecting the content of the interference.

I now move to show how the decisions of choice architects who are designing nudges satisfy $b$ and $c$. That is, their decisions are not effectively constrained by some procedure and their decisions do not have to track "the shared ideas [of those subject to interference] as expressed through suitably-structured deliberative procedures". First, I

${ }^{45}$ Bubb and Pildes (2014, p. 1618). 
want to show that their decisions do not have to track the shared ideas of choosers. The most likely candidates for such ideas are the well-formed preferences or anticipated choices of choosers. But, part of what makes nudging paternalistic is that choice architects "are not trying to track people's anticipated choices, but are self-consciously attempting to move people in welfare-promoting directions." ${ }^{\text {46 }}$ If the shared ideas that have to be tracked to make a decision nonarbitrary are the anticipated choices of choosers, and choice architects are not trying to track these anticipated choices, then those decisions may be arbitrary.

Secondly, Sunstein and Thaler view the fact that people have cognitive biases as evidence that people do not have well-formed preferences in cases where the biases are effective. ${ }^{47}$ If choosers are assumed to lack well-formed preferences, and the ideas that choice architects are supposed to track to make their decisions nonarbitrary are such preferences, then there is nothing for them to track. So, if the ideas are just the wellformed preferences of choosers, then the decisions of choice architects may be arbitrary.

Further, there is reason to doubt that the decisions of choice architects can be effectively constrained by any procedure. Any review procedure of the decisions of a choice architect would be conducted by individuals who have cognitive biases. One of which would be a bias towards the default option, which is whatever the choice architect has chosen. Because the decision of a choice architect is likely to influence the review process, that decision likely cannot be effectively constrained.

Two other reasons should be looked at for why there is likely to be no procedure that can effectively constrain the decisions of choice architects. First, choosers are likely

\footnotetext{
46 Thaler and Sunstein (2009, p. 1162).

47 Thaler and Sunstein (2009, p. 1161).
} 
to think that the decision of the choice architect is the decision of an expert who should be deferred to. Sunstein and Thaler suggest that nudges should be used in situations where individuals do not have the incentives to be fully informed, have little experience making similar choices, or there is little feedback about their choice. ${ }^{48}$ In such cases, we should expect choosers deliberating over the decisions of choice architects to be partial to the status quo, but not because their deliberation has led them to see that the status quo is best. Rather, they "may assume (perhaps unconsciously) that someone with expertise must have thought the default plan was a good one". ${ }^{49}$ And, in the kind of cases where there is little incentive to be fully informed, there is little incentive to find out that the choice architect's decisions are not optimal.

Finally, as noted in the first section, individuals are susceptible to an anchoring bias. Again, anchoring occurs when choosers must select from a spectrum of options and they are influenced by the initial value they are exposed to. Why this is concerning in this context is that even if a chooser is going to deviate from the decision of the choice architect, the architect's initial decision is likely to serve as an anchor that will influence the deviation more than it otherwise would.

It is not enough for the defender of the use of nudges to note that he or she is committed to choosers' being able to opt-out of the default option and that an opt-out seems to be exactly the kind of process that should qualify as a deliberative procedure where the chooser is able to express his or her ideas about the interference. As Bubb and Pildes note, in some contexts the presence of an opt-out produces the "illusion of choice

\footnotetext{
48 Thaler and Sunstein (2009, p. 72).

${ }^{49}$ Whitman, Douglas Glen and Mario J. Rizzo (2007, p. 433-434). See also, Sunstein and Thaler (2003, p. 1181).
} 
that has little consequence" because while there is formally an opt-out option the consequences of the nudge are nearly the same as a mandate. ${ }^{50}$ The concern is that because of the biases of choosers that choice architects take advantage of to influence choices, there can be no effective deliberative procedure available to choosers free from the influence of the architect's decisions. Sunstein and Thaler note that, "In many settings, any starting point will carry some informational content and will thus affect choice". ${ }^{51}$ Choosers seem unable to escape the influence of a choice architect's decision so as to be able to review it absent the architect's influence. So, attempts to constrain an architect's decision will be subject to the influence of the architect.

Because nudge-designing choice architects have the capacity to interfere, can decide the content of their interference, do not have to track the shared ideas of those subject to the interference, and there is no effective procedure to constrain their decisions, they have the capacity to arbitrarily interfere with choosers. For this reason, they stand in a position of domination and thus those being nudged are unfree. This is true even of some of those for whom the choice architect's selection is ideal because they could have been nudged into a nonoptimal direction.

The line of argument that I am advancing is distinct from the traditional objections to libertarian paternalism. Any objection that appeals to the harms done by constructing a particular choice architecture only shows that there is something contingently wrong. Perhaps a finer-grained intervention could fix the harms being done. However, my line of argument notes that all choosers are made unfree (so long as they are subject to cognitive biases that can be exploited), not merely those who are actually

\footnotetext{
${ }^{50}$ Bubb and Pildes (2014, p. 1599).

${ }^{51}$ Sunstein and Thaler (2003, p. 1180).
} 
being harmed. Even if the choice architect selects a choice architecture that is in an individual's best interest and increases his or her welfare, the architect could have arbitrarily chosen otherwise, could have arbitrarily interfered, and therefore even that individual is unfree. Further, if one assumes that there is a side constraint against doing actions that increase domination, then one can conclude that nudging is impermissible.

\section{Domination as Graduated or Non-Binary}

To this point, I have assumed that domination is binary and that the way to show that nudging is impermissible is to assume that there is a side constraint against doing actions that increase domination. One might object that it is not clear that domination cannot come in degrees nor that there is a side constraint against infringing on the republican freedom of others. I grant that these may not be assumptions that are intuitive to everyone. However, I do hope that for those that find these assumptions acceptable, I have shown that the use of nudges is impermissible.

For those that do not find these assumptions acceptable, I now want to make the case that a republican analysis of the use of nudges still has value. To show this, I want to relax these assumptions and show how a republican analysis can allow one to determine the factors that delimit the scope of permissible nudges when one assumes that republican freedom has some value.

I want to consider three ways to relax the assumption that there is a side constraint against the infringement of republican freedom. These ways may not be exhaustive, but I hope they are the main alternatives. The first way is to assume that there is a threshold 
that separates permissible from impermissible degrees of infringement. ${ }^{52}$ The second way is to assume that republican freedom is one of many things of value along with things like welfare. ${ }^{53}$ The big difference between these two views is that on the first, if there is a violation of republican freedom that exceeds the threshold, then it is impermissible even if it produces great amounts of welfare or other things of value. On the second view, any degree of violation of republican freedom could be justified so long as it produces enough of an increase in the other things of value. The final way is to assume that republican freedom only has value to the extent that it promotes or constitutes whatever has ultimate value. For example, if republican freedom has value because respecting it tends to promote welfare, then it may be infringed when doing so does not diminish welfare.

It is not clear to me that either of these ways of considering republican freedom are obviously correct or incorrect. Nor does it seem obvious that advocates of nudging commit themselves to one of these views. The third option is similar to Sunstein's treatment of autonomy in Why Nudge?, and this may be evidence that advocates of nudging are committed to that approach. However, such an approach seems to also justify hard paternalism, which should be unacceptable to libertarian paternalists. Similarly, the second approach also seems capable of justifying hard paternalism. ${ }^{54}$ Thus, in relaxing the assumption that there is a side constraint against violating republican freedom, I will assume a threshold view. I will not argue for a particular threshold, but will merely

\footnotetext{
52 One concern that one might have is that a threshold is simply a form of side constraint. In a sense this is correct, but there is an important difference. A side constraint against doing actions that increase domination implies a ban against such actions. A threshold implies that an action may permissibly increase domination some amount. I thank Paul Weirich for raising this concern.

${ }^{53}$ I will not provide a definition of welfare here. One may use whatever account one prefers.

${ }^{54}$ Under the second and third approaches, one would not have to respect republican freedom if a hard paternalist policy that violates that freedom would maximize overall value. Further, one could be justified in using hard paternalist policies in place of nudges when doing so maximizes overall value.
} 
assume that one exists. Finally, though I am assuming the threshold view, it seems plausible that advocates of nudging could endorse the other approaches.

Given that one is dominated if and only if another has the capacity to arbitrarily interfere with him or her, there seem to be two axes on which violations of republican freedom can come in degrees. There can be a capacity for more or less interference or there can be a capacity for more or less arbitrariness. ${ }^{55}$ The way I will analyze how the capacity for interference and arbitrariness can come in degrees is by looking at what elements of their definitions can obviously come in degrees. ${ }^{56}$

First, let us return to the portions of the definition of interference that are relevant for analyzing nudges. One has the capacity to interfere if one can intentionally make things worse for another through the use of tactics like "the deceptive or non-rational shaping of people's beliefs or desires" or intentionally worsening the perception of the expected payoffs and benefits of available options. ${ }^{57}$ One's capacity to make things better or worse for someone can come in degrees when nudging. For example, a cafeteria worker can likely only make you pay a little more or cause you to eat a little less healthily when nudging you. So, his or her capacity to interfere with you seems small. A physician might be able to nudge you into having an expensive or risky procedure and in this way has a large capacity to interfere. Thus, if arbitrariness is held constant, then the amount of domination seems to vary as the capacity to interfere varies.

\footnotetext{
${ }^{55}$ Lovett (2001) has an alternative account of domination where domination can come in degrees. I will not explore his account here.

56 There is some danger of my committing the fallacy of composition by using this approach. However, it is not clear how domination could come in degrees when the conditions for domination are binary. Thus, I will assume that for domination to come in degrees some aspect of the conditions of domination must be graduated.

${ }^{57}$ Pettit (1997, p. 52-53).
} 
If the threshold view is adopted for dividing permissible from impermissible interferences of republican freedom, then holding arbitrariness constant, the use of nudges places choice architects with large enough capacities to interfere into a position of impermissible domination over choosers. So, it may follow that only some individuals may permissibly nudge and others may not permissibly nudge because their capacity to interfere is too great.

The second axis for thinking about graduated domination is considering if arbitrariness can come in degrees. Recall that for one to have the capacity to interfere arbitrarily, three conditions must be met: a) whether or not the interference occurs, or its content, is the choice of the interferer, b) the capacity to interfere is not effectively constrained by some procedure, and c) the interferer does not have to track "the shared ideas [of those subject to interference] as expressed through suitably-structured deliberative procedures". There may be ways to show that one has a greater or lesser capacity to decide if an interference occurs. For example, a shareholder controlling fortynine percent of the vote seems to have a greater capacity to determine if an interference occurs than a shareholder who controls three percent of the vote. But, for the sake of simplicity, I will assume that choice architects either can or cannot satisfy condition $a$ as opposed to satisfying it to some degree.

It also seems as though condition $c$ is plausibly binary. While an argument could be made that deliberative procedures can be more or less suitably structured, I will put aside such issues as I have argued that choice architects are not trying to track the shared ideas of those subject to the interference. So, it is irrelevant if the procedure for expressing those ideas is more or less suitable. 
Condition $b$ seems to be the one that is most clearly plausibly graduated. It does seem that procedures can be more or less effective at constraining the capacity for a choice architect to interfere. One way of thinking of how a procedure can be more or less effective is by seeing how likely the procedure is to prevent the interference. For example, if a doctor tries to nudge a patient, then a procedure that more or less effectively constrains the doctor's interference is the patient's deliberation on whether or not to consent. If the procedure is wrong for the patient, then the more likely the patient is to withhold consent, the more likely the procedure seems to be effective at constraining the doctor's capacity to interfere. The less likely the patient is to withhold consent, then the less likely the procedure is to constrain the capacity to interfere and the greater the doctor's capacity to arbitrarily interfere.

In the previous section I argued that it is unlikely that there can be an effective procedure for constraining the capacity of choice architects to interfere. I claimed that the various biases that supposedly justify nudging make it unlikely that there will be deviation from the decisions of choice architects. The less likely that individuals are to try to avoid the interference of a choice architect the less effective any procedure is for constraining the architect's capacity to interfere. And, assuming a constant amount of interference, the greater the infringement of republican freedom, perhaps to the point of being an impermissible infringement.

Combining these points together, it can be concluded that if there is a threshold of permissible infringement of republican freedom, then the use of nudges by some choice architects may be permissible. That is, if the architect's capacity to interfere is sufficiently small or choosers who would be harmed by the nudge are sufficiently likely 
to avoid the nudge, then the use of nudges by the architect is permissible. ${ }^{58}$ However, if the capacity to interfere is sufficiently large or the likelihood that choosers would avoid the nudge (given that it interferes with them) sufficiently small, then the use of nudges by the choice architect would be impermissible. Such an architect would stand in a position of domination over choosers. In this way, we can delimit permissible from impermissible nudges with a republican account that treats domination as something that can come in degrees.

\section{Boosting as an alternative}

Before considering objections to the two accounts that I have given, I want to consider how boosting fares as an alternative to nudging.

Boosting does not diminish republican freedom; it may in fact increase it. Unlike nudges, boosts do not count as interferences on the account provided earlier. Boosts are not used to intentionally worsen the perception of expected payoffs and benefits of available options, but instead aid choosers in more accurately understanding the benefits and costs associated with those options. Nor are boosts used to non-rationally shape people's beliefs and desires. They simply do not seem to be things that can be used to make one worse off. And, if boosts cannot be used to interfere, then they cannot be used to interfere arbitrarily. So, the use of boosts cannot place boosters in a position of domination over choosers. Further, strategies imparted when boosting may help choosers

\footnotetext{
${ }^{58}$ It is not clear if the amount of interference and the degree of arbitrariness should be evaluated separately or combined. It may be that rather than a threshold of infringement of republican freedom there should be separate thresholds of the capacity to interfere and the degree of arbitrariness. Or, it may be that any amount of interference is unacceptable if the degree of arbitrariness is great enough and vice versa. I will assume that the degrees of infringement and arbitrariness should be combined, but the account can be amended to accommodate other views.
} 
avoid the interference of others and in this way, may increase the republican freedom of choosers.

If I am correct that boosting does not diminish republican freedom but nudging does, and there is a side constraint against diminishing the republican freedom of others, then boosting is a morally preferable alternative to nudging. However, if there is no such side constraint and domination comes in degrees, then the preference for boosting over nudging will depend on the costs associated with boosting.

As I noted in the previous chapter, boosting can require an initial investment of resources and effort of the part of the individual being boosted, particularly when he or she has to learn a new strategy. On the view that domination can come in degrees, nudging may be preferable so long as the infringement of republican freedom does not exceed the threshold and the cost of boosting is sufficiently high. I admit that I have to accept this as a consequence of what I have argued thus far.

I also noted that a potential cost associated with boosting is the loss of the option to nudge choosers in the future. A boost might permanently debias a chooser such that future nudges would not be effective. On the threshold account of domination, one could permissibly maintain this option value by employing nudges so long as the amount of

domination does not exceed the threshold. Otherwise, the option value of nudging would have to be given up and a boost (or other permissible intervention) used.

\section{Objection - Boosting to make an effective constraint on evaluators}

The first objection I want to consider is one that turns my own weapon against me. One might claim that boosts can be used to nullify the republican objections that I raise 
against the use of nudges. The argument may go as follows: I have argued that there can be no effective procedure for constraining the decisions of choice architects. The reason why there cannot be such a procedure is that anyone reviewing the decisions of choice architects would have cognitive biases of his or her own and those would include a default bias and an anchoring bias. This means that the decisions of a choice architect would influence the review procedure. In certain cases, it may be possible to boost those who are reviewing the decisions of choice architects such that they are free from these influences. Under these conditions, nudging would not violate republican freedom because an effective review procedure could be constructed.

I admit that I am skeptical that there would be many of these cases. The use of such a system requires either boosting choosers or boosting individuals who can review the decisions of choice architects but are not themselves choosers subject to the nudge being reviewed. If one opts for boosting choosers, then it is not clear why one would boost them such that they could review the decisions of the choice architects when they nudge them. It seems that one would simply boost them to deal with their choice environment absent the use of nudges instead of nudging them and boosting them so that they may better deal with their choice environment's including nudges. Further, it seems that cases where one would have a panel that reviews the decisions of choice architects would be rare. But, I suppose if there are cases where it is possible, then my republican account has to accept that the use of nudges in those cases is not impermissible on republican grounds (though, they may be impermissible for other reasons).

\section{Objection - Choice architects are bound by a standard}


The next objection denies that choice architects stand in a position of domination over choosers. Specifically, it denies that choice architects can act arbitrarily. I have constrained what counts as a nudge by the standards of libertarian paternalism. Given that I understand that nudges must be intended to be beneficial to the choosers, choice architects are constrained. They may have the capacity to interfere and they may have the capacity to arbitrarily decide if they will nudge or not, but they do not arbitrarily interfere when nudging. They must intend to track welfare and this limits the ways they may interfere.

This form of objection rejects the definition of arbitrariness that I presented above. The objection can still allow that a choice architect has the capacity to interfere, and it can allow that a choice architect chooses the content of that interference. But it rejects that the architect's capacity to interfere must be effectively constrained by some procedure and that the architect does not have to track the shared ideas of those subject to the interference in order to render the capacity to interfere nonarbitrary. It inserts a new condition. That is, it holds that an interference is nonarbitrary when it is must be well intentioned. Unfortunately, it is false that, if an interference is well intentioned, then it is nonarbitrary.

We can broadly think of republicans as wanting to reduce domination. Plausibly, part of the motivation for doing so is to prevent the harms that can occur when accidents happen and the best intentions lead to disastrous results. That is, republicans would like to stop paving the road to hell with all of those good intentions. To understand why, consider what advice republicans would provide to the slave with the benevolent owner compared to the advice that is compatible with the view that what matters is freedom as 
noninterference. Republicans would advise the slave to ignore that his or her master has been benevolent and, in order to be free, stop being a slave. The advice would be to remove him or herself from a condition where another has the capacity to exercise so much power over him or her. Those who advocate for freedom as noninterference could advise the slave to try to make his or her master a better person to ensure that the master continues to be benevolent and does not interfere with the slave. ${ }^{59}$ But, this is the wrong advice. The master could be mistaken about what is good, and with the best intentions, exercise his or her capacity to do great harm. Connecting arbitrariness to intentions does not restrain the capacity to interfere in a way that conforms with republican motivations. Thus, republicans would and should deny that if an interference is well intentioned, then it is nonarbitrary.

\section{Objection - Failed to capture what is objectionable about nudging}

In this chapter, I have attempted to explore a way to object to the use of nudges and in doing so determine some conditions for when nudging may be impermissible on republican grounds. However, in doing so, I may have failed to capture all of the reasons that nudging may be impermissible. This would give one reason to believe that a republican analysis fails to explain what is objectionable about nudging. For example, nudges that conform to William Glod's Neutral Nudge Principle would not be arbitrary. That principle is that "Whatever one's first-order preferences or values, nudgers properly so-called will only aim to (non-deceptively) manipulate one in order to bring one's actions back into alignment with one's own preferences or values, inasmuch as one has

${ }^{59}$ Unfortunately, I can no longer find the reference for this example. However, it is not my own. 
well-defined preferences or values" ${ }^{60}$ Choice architects that have to satisfy the Neutral Nudge Principle would not have the capacity to interfere arbitrarily since they would have to track the preferences of individual choosers. However, one may still feel uneasy about the use of nudges that satisfy the principle and believe that they are impermissible. So, the objection may go, republicanism fails to explain what is objectionable about nudging since one would have to appeal to a non-republican reason to explain why such nudges are impermissible. It would then be that reason that explains why nudges are impermissible.

I share the concern that republicanism may not explain why all impermissible nudges are impermissible. However, it does not follow that republicanism cannot play a role in explaining why some nudges are impermissible. It may simply be overdetermined why some nudges are impermissible. In such a situation, the republican analysis gives one of many possible explanations for why some nudges are impermissible. Republican tools do have the advantage of enabling one to identify that there is something problematic about the ability of choice architects to arbitrarily make one worse off. But, I do not believe that republicanism has the only tools for determining what explains the wrongness of nudging. ${ }^{61}$ And, I am skeptical that there is a single explanation that captures all the wrong-making features of nudging such that a republican explanation would be redundant.

\footnotetext{
${ }^{60}$ William Glod (2015, p. 605-606).

${ }^{61}$ In the next chapter, I will advocate for one of these alternative ways of objecting to the use of nudges.
} 


\section{Chapter 3: Nudging Is an Achievement That Threatens Other}

\section{Achievements}

Every once in a while, I take advantage of the fact that I can walk past Thomas

Jefferson's original tombstone. He designed it himself, a "die or cube of 3.f without any mouldings, surmounted by an Obelisk of 6.f. height, each of a simple stone: on the faces of the Obelisk the following inscription, and not a word more

'Here was buried

Thomas Jefferson

Author of the Declaration of American Independence

of the Statute of Virginia for religious freedom

\& Father of the University of Virginia.'

Because by these, as testimonials that I have lived, I wish most to be remembered." 62

These were the achievements of Thomas Jefferson as he saw them and

presumably as he wished we would see them. And, though for most of us our

achievements pale in comparison, our achievements play a similar role in defining how we see ourselves, how we see others, and how others see us. For example at the time of this writing, Simone Biles recently became Olympic champion Simone Biles. By May, a number of graduate students will have achieved their goal of completing their education and they will be defined as Dr. So-and-So. Every January $1^{\text {st }}$, many people set out to achieve something that is important to them over the course of the year. These

${ }^{62}$ Jefferson's untitled memo on which he wrote this can be found here: http://memory.loc.gov/cgibin/ampage? collId=mtj1\&fileName=mtj1 page055.db\&recNum=1134 
achievements, great and small, are in some way the marks we leave on the world, and for that reason, they can serve this defining role.

In this chapter, I advance two arguments concerning nudges and achievements. First, I argue that the use of nudges can prevent some achievements from qualifying as achievements. Secondly, I argue that for those that still qualify as achievements, nudges can diminish the value of those achievements. While I will not provide a conclusive case against nudging, I will point to a consideration against nudging that I believe has been unaddressed.

To make these arguments, I adopt Gwen Bradford's account of achievements and I assume that achievements are important and valuable parts of our lives, particularly when they are life-defining. ${ }^{63}$ I structure my discussion as follows: First, I give a general summary of Bradford's account of what is required for something to be an achievement. I then explain how nudges can keep would-be achievements from qualifying as achievements. I then explain what gives achievements value as achievements and argue that those achievements that are produced by nudges but still qualify as achievements are less valuable than they otherwise would be. I think boosting fares well as an alternative, so I briefly explore how these concerns apply to it. Finally, I consider several objections and counter-considerations.

\section{Bradford's account of achievements}

${ }^{63}$ Specifically, I will be drawing from Bradford's 2015 book Achievement. 
Bradford says that "achievements are comprised by a process and product, where the process is difficult, and competently causes the product".${ }^{64}$ So, in evaluating if something is an achievement, we cannot simply ask if some product was produced, we must also assess features of the process involved. It should be noted that this account does not dismiss the possibility that the process is the product. For example, climbing Mount Princeton might be an achievement even if one's doing so does not produce a tangible product. The process is the climb and the product is having completed the climb.

The restrictions on the process are that it must be difficult and the process must have competently caused the product. Difficulty here is understood in terms of effort. For a process to qualify as being difficult, an agent must have expended a certain amount of effort that exceeds some minimum intensity. That is, some sustained but sufficiently lowintensity activity will not count as being difficult no matter how long that activity is done. The only effort that counts towards a process's being difficult is effort that exceeds the minimum threshold. I will not argue for a particular threshold but simply hold that some threshold exists. I also will not state a particular amount of effort as the minimum required for a process to be difficult but will hold that there is some minimum.

Of course, exerting a lot of effort is not enough to make something an achievement. After all, if I set out to climb Mount Princeton and instead end up atop Mount Yale ${ }^{65}$ I haven't achieved anything. ${ }^{66}$ Rather, to be an achievement, an agent must have competently caused the product. Competent causation here requires that the agent,

\footnotetext{
${ }^{64}$ Bradford (2015, p. 25).

${ }^{65}$ We can assume (fairly accurately) that it would take an equal amount of effort to climb either.

${ }^{66}$ Richard Lauer and Alastair Norcross have separately noted in conversation that you seem to achieve something, just not climbing Mount Princeton. I think this is mistaken since you, by your own lights, failed to do what you set out to do and one cannot fail and achieve at the same time.
} 
when engaging in an activity that produces some product, have a required number of justified true beliefs about the activity's causing the product. The required number of justified true beliefs [JBTs] are some percentage of "the total possible beliefs about the activity, and JTBs that are about the overall structure of the activity are worth more than

discrete beliefs" ${ }^{67}$ To return to the above example, my false belief that the route I took up the mountain would lead me to the summit of Mount Princeton and not Mount Yale is sufficient to say that I did not competently cause my climbing Mount Yale, and I therefore cannot claim the climbing of Mount Yale as an achievement. I will not argue for a particular percentage of justified true beliefs as the threshold for competent causation, but I will hold that such a threshold exists.

\section{Nudges threaten the status of would be achievements}

Recall that I adopted the following definition of "nudge" from Hansen: "a function of (I) any [intentional] attempt at influencing people's judgement, choice, or behavior in a predictable way, that is (1) made possible because of cognitive boundaries, biases, routines, and habits in individual and social decision-making posing barriers for people to perform rationally in their own self-declared interest, and which (2) works by making use of those boundaries, biases, routines, and habits as integral parts of such attempts. Thus a nudge amongst other things works independently of: (i) forbidding or adding any rationally relevant choice options, (ii) changing incentives, whether regarded in terms of time, trouble, social sanctions, economic and so forth, or (iii) the provision of factual information and rational arguments". ${ }^{68}$ I further constrained what counts as a nudge by

\footnotetext{
${ }^{67}$ Bradford (2015, p. 145).

${ }^{68}$ Hansen (2016, p. 20).
} 
stipulating that the intervention must have been used with the intent of improving choosers' lives without trying to anticipate their choices to count as a nudge.

There are two ways that nudges can threaten something's being an achievement. The first is by reducing the effort required in producing the product. If the nudge reduces the effort required for doing something such that it does not meet the threshold required for qualifying as difficult, then the activity cannot be an achievement.

For example, consider Saving Sally. Through her life Saving Sally works hard on saving for retirement. She makes various sacrifices to save at an appropriate rate, as she gets older she shifts more of her investments from stocks to bonds, and she engages in other activities such that her sustained effort meets the difficulty threshold for being an achievement. Sally also has enough justified true beliefs about investment strategies and the like to meet the JTB requirement for achievements. When she retires early, we can safely declare her saving for retirement as being an achievement.

We can also imagine a nudge that makes saving for retirement significantly less difficult. Sunstein and Thaler describe a program they call "Save More Tomorrow". Because of loss aversion, people are hesitant to immediately increase their savings rate by increasing their contributions to their $401(\mathrm{k}) \mathrm{s}$. It hurts to see your paycheck decrease. Save More Tomorrow is a plan where employees agree, either implicitly or explicitly, that whenever they receive a raise in the future, the percentage of their paycheck that is automatically placed into their $401(\mathrm{k}) \mathrm{s}$ increases until it hits a maximum contribution rate. This way, they do not take home a smaller paycheck in unadjusted dollars and do not perceive increased retirement savings as losses even though they may be taking home less in adjusted dollars if the raise simply matches an increase in the cost of living. The 
plan is also designed to take advantage of people's tendency toward inertia. That is, people will not expend effort in the future to decrease their savings rate because they have a bias towards inaction. ${ }^{69}$

This plan is supposed to make it easy for people to save for retirement. They simply set it, forget it, and allow the automatic increases in the contribution rate to bring them to a rate that allows them to comfortably retire. Further, they do not have to suffer the cognitive costs of seeing their paychecks go down in unadjusted dollars.

Because Save More Tomorrow makes things easy, one who saves for retirement with this program cannot be said to have achieved something by saving for retirement. This program precludes one from being able to have an achievement like Saving Sally's without opting out of the program. But of course, the program is designed such that inertia keeps people from opting out.

The other way that nudges can threaten something's qualifying as an achievement is if they prevent an agent from acquiring or possessing sufficient JTBs to qualify as competently causing the product. For example, a nudge could disincentivize someone from altering their current strategy until they can competently cause the desired product. Consider the following example. It can be an achievement to lose a significant amount of weight. It can be very difficult when there is consistent temptation to eat various kinds of foods. One can competently cause his or her own weight loss by having JTBs about what an appropriate diet would be. But, if one is nudged into losing weight, then his or her weight loss may no longer count as an achievement.

${ }^{69}$ Thaler and Sunstein (2009, p. 114-115). 
Consider the case of Otherwise-Achieving Amy. Amy decides she wishes to lose a significant amount of weight. She is committed to doing so and will keep trying strategies until she finds something that works. She hears about a new fad about "burning mental calories". All you have to do is engage in a highly difficult mental activity for long periods every day and the pounds will disappear. You don't even have to change your eating or exercise habits. Of course, the diet won't work, but Amy's boss Nudging Ned recently read Nudge and has decided to reorganize the company cafeteria. The plates have been made smaller to encourage smaller portions. The cups are smaller and the soda fountain is more difficult to find while water is prominently displayed. And, while moving through the cafeteria, healthy foods are encountered before unhealthy ones. Amy engages in her rigorous mental exercises and continues her habit of eating in the cafeteria. And, after a short time, she notices that she is losing weight until she reaches her goal.

Otherwise-Achieving Amy has not achieved something by losing weight. She attributes her success to her mental exercises and is unaware of the changes Ned made to the cafeteria and their role in causing her to lose weight. Because of the nudge, she has reached her goal but fails to have sufficient JTBs to qualify as having achieved something. Further, if not for the unnoticed nudge, we can stipulate that she would have kept trying things until she found a program that causes her weight loss and allows her to have sufficient JTBs such that her weight loss is an achievement.

What we can conclude is that nudging can prevent someone from doing activities that may otherwise qualify as achievements. It can reduce the difficulty of the activity such that it is not sufficiently difficult. It can also allow people to continue to hold false 
beliefs that prevent them from qualifying as competently causing the product. This can be true even in cases that can be personally defining such as losing significant amounts of weight.

This argument is not sufficient for showing that there is something in-principle wrong with nudging. What it does do is reveal a potential cost of nudging. And, it seems that there may be conditions where this additional cost means that there is an all-thingsconsidered case against a particular nudge. For example, it might be better to allow Amy to try her fad diet, fail, and experiment until she finds something that works such that her weight loss is an achievement. This is especially true if her weight loss can be the kind of thing that can define her life or it carries great personal importance that she be responsible for her weight loss.

\section{The relative value of achievements}

It may strike one as implausible that nudges can decrease the difficulty of an achievement or reduce the percentage of JTBs required to do an activity to a degree that is sufficient to threaten the status of many or any achievements. That is, it may seem implausible that there are many marginal achievements. It may strike one as implausible that there are a great many achievements where the process is barely difficult enough to exceed the threshold or the agent has just enough JTBs to exceed the threshold such that a nudge would render the activity a non-achievement. So, a possible objection may go, while I may have identified a potential concern one does not need to worry about the possibility of a nudge rendering a would-be achievement into a non-achievement because such cases will be rare. 
I want to resist this line. However, even if one endorses it, there is still something potentially concerning about the use of nudges as it relates to achievements. A nudge can make an achievement less valuable.

Not all achievements are of equal value. On Bradford's account, what makes one achievement more valuable than another relates to its degree of difficulty and the degree to which the product was competently caused. ${ }^{70}$

Bradford explains the value of achievements from the perfectionist perspective that the excellent exercise of characteristically human capacities is intrinsically valuable. ${ }^{71}$ Doing something difficult has value because doing difficult things requires the exercise of a perfectionist capacity, the will. Competently causing something requires the exercise of another perfectionist capacity, rationality. So, achievements have value because they require the exercise of perfectionist capacities. Some achievements have more value than others because they require a greater exercise of those capacities. That is, the more difficult and the more competently caused, the greater the achievement.

But, one need not accept perfectionism to accept that more difficult achievements have more value than less difficult ones, and the same applies to competent causation. After all, it seems correct that winning a bronze medal can be a greater achievement than winning a gold medal when the bronze medalist overcomes greater difficulties than the gold medalist. ${ }^{72}$ It is plausible that what explains this is that degree of difficulty

\footnotetext{
${ }^{70}$ For the purposes of this paper, I will not be addressing achievements as organic unities and the role that unity in diversity plays toward the relative value of achievements. However, the account I give here can be augmented to show that a diminishment of either difficulty or competent causation has a larger impact on the value of an achievement than the degree of that diminishment if it decreases the amount of unity in diversity.

${ }^{71}$ Bradford (2015, p. 115).

72 Bradford (2015, p. 92-93) gives the example of Silken Laumann who had to overcome a significant leg injury sustained 10 weeks before the Olympics as an example of a bronze medalist whose achievement is greater than that of the gold medalist.
} 
contributes to the value of an achievement. The threat that nudging presents is that a nudge might decrease the difficulty or competent causation required during some process such that even if the process is sufficiently difficult and competently caused to count as an achievement, it will be less valuable as an achievement. The process will have required less effort or competent causation, and therefore, it will be less valuable as an achievement than it otherwise would have been. So, even if a nudge does not preclude something's being an achievement, it can make it a less valuable achievement.

\section{Boosting as an alternative}

To this point, I have advocated for boosting as an alternative to nudging. But, one may be concerned that the objections I raise here against nudging might also apply to boosting. That is, boosting might make it easier to do an activity, which would threaten that activity's status as an achievement or make it less valuable of an achievement.

I do have to grant that this is possible. But, as noted in the first chapter, boosts increase the competence of choosers. So, it is plausible that boosts increase the degree to which an agent competently causes the product when engaging in some process. When compared to nudges, which we should expect to only reduce competent causation, boosts are less of a threat to something's being a valuable achievement. Further, there may be cases where the increase in competent causation created by a boost more than offsets the decline in difficulty that it creates. In such a case, a boost can make it more likely that something qualifies as an achievement or increases its value as an achievement. The same cannot be said for nudges as they seem to only be able to reduce a chooser's competent causation by causing him or her to reason or act in biased ways. 


\section{Objection - Welfare}

There are two welfare-related objections to the argument I have presented. The first objection does not refute my conclusion but does shows how modest the conclusion is. The second challenges my conclusion by questioning the value of achievements.

The first objection is that people are unlikely to accomplish these would-be achievements. If people were likely to do things like save for retirement or lose significant weight, then there would be little motivation to design nudges to help people do these things. Given that people are unlikely to do these activities and there might be great welfare gains if people saved or lost weight, then it is not wrong to nudge in these and similar cases because of the expected welfare gains.

I can grant that this is true. If there are great welfare gains to be made, then it might be worth sacrificing the people's capacity of realizing these gains in ways that make them achievements. After all, it seems that laws that prevent people from harming others are acceptable even though may prevent people from achieving certain things. However, it is still plausible that there may be cases where the expected welfare produced by a nudge is small enough, or the value of an achievement large enough, that nudging would seem unjustified. So, an appeal to achievements can still serve as part of an allthings-considered case against nudging.

The second welfare-related objection challenges the value of achievements by employing a strategy Sunstein uses against the value of autonomy. In Why Nudge?, Sunstein speculates that those who object to nudging on autonomy grounds may be making a simple mistake. What really matters to objectors may not be autonomy as 
something with value in itself but welfare. They (perhaps correctly) believe that autonomy is conducive to promoting welfare and mistake autonomy as having independent value. They mistake a means to an end as having value independent of its ability to produce that end. As Sunstein puts it, "People speak in terms of autonomy, but what they are doing is making a rapid, intuitive judgement about welfare" ${ }^{73}$ If this speculation is correct, then an advocate of nudging does not have to argue that a nudge does not violate autonomy but instead should argue that the nudge better promotes welfare than respecting autonomy does.

The same line of reasoning could plausibly be waged against one who takes achievements as being valuable. Perhaps achievements have value simply because achievements are a means to welfare or they are independent of but often correlated with welfare. Either way, they aren't prerequisites to having welfare. And these hypotheses match the general observation that the more one achieves in his or her life, the greater his or her welfare. The defender of achievements makes a mistake by incorrectly thinking that achievements have value independent of the welfare they are often associated with. So, it should not be an issue that nudging may preclude one from having certain achievements when nudges promote welfare.

There are a variety of ways of responding to this objection. The one I favor relies upon a classic philosophical thought experiment: the experience machine. ${ }^{74}$ What the experience machine is supposed to show is that we want to do certain things. ${ }^{75} \mathrm{We}$ don't want to just have the experience of doing an activity, we want to actually do it. A

\footnotetext{
73 Bradford (2015, p. 134).

${ }^{74}$ Bradford uses the experience machine to explore achievements as organic unities. My use of the experience machine here is inspired and informed by her use of it (p. 125).

${ }^{75}$ Nozick (2013, p. 43).
} 
reasonable explanation for why we have this preference is that we desire to competently cause some outcomes. Consider your making two climbs of Mount Yale, one within the machine and the other outside of it. The difficulty experienced is the same in both, but you can only competently cause your climb outside the machine. This is because the beliefs you have about the climb while in the machine are false. On the view that achievements do not have value independent of welfare, the welfare produced by both climbs should be the same and the value of both climbs should be the same. But this doesn't seem right. There seems to be more value to the climb performed outside the machine. So, either competent causation has value independent of welfare, which makes achievements valuable, or achievements have value independent of welfare. ${ }^{76}$

\section{Objection - Nudge to make things more difficult or require greater exercise of rationality}

One possible objection is that the line of argument I have pursued might have an absurd implication. The implication is that if achievements are valuable, perhaps we should use nudges to make things more difficult for people. The objector may turn Milton Friedman's famous rhetorical question against us and note that if a group of workers are trying to dig a canal, and it would be a more valuable achievement were it more difficult, then why don't we restrict them to using spoons?

\footnotetext{
76 This disjunct at least seems plausible. However, it is possible that I have committed the fallacy of composition. That is, it may be that competent causation has the property of being valuable but achievements, the whole of which it is a part, does not have this property. But, since our intuitions are that more competently caused achievements are more valuable than less competently caused but equally difficult achievements, it is unlikely that the fallacy has been committed here.
} 
This objection helpfully shows that we care about more than just achievements. For example, we often care about having regular access to food rather than having the achievement of tracking and hunting game. We often care more about the convenience of buying a home than we do the achievement of building our own. I do not want to suggest that we should give up these preferences for having easy modern lives. I only want to suggest that nudging might have a cost that was previously unaccounted for and that in some cases, that may be enough to say that one shouldn't nudge.

\section{Objection - Nudging now allows for more achievements later}

One might object that if I really care about achievements, then I should be in favor of the use of nudges. The objection would parallel one that Sunstein uses against those who object to the use of nudges on autonomy grounds. The claim is that by nudging, one can increase the health and wealth of choosers. This added health and wealth allows choosers to have longer lifespans such that they can make more choices and have more means for doing things they may wish to do in the future. ${ }^{77}$ This means that nudging now allows for greater exercise of autonomy when measured over the course of the nudgee's life.

Applied to achievements, the objection would be that by being nudged into greater health and wealth, one can have even more achievements over the course of one's life. For example, being nudged into saving more for retirement would allow one to have more means with which to pursue various achievements when one retires.

There are two concerns with this objection. First, if interventions today are justified by the potential for more achievements in the future, then nudges would seem to

\footnotetext{
${ }^{77}$ Sunstein (2014) makes roughly this point.
} 
be half measures. One could reduce the likelihood that choosers would miss out on these future benefits by engaging in hard paternalist interventions instead. ${ }^{78}$ The objection that I should be in favor of more nudging in order to generate more health and wealth so that people can enjoy more achievements over the course of their individual lifetimes seems to justify hard paternalist interventions. However, libertarian paternalists should want to reject justifications of hard paternalism. So, they should not endorse the argument that one can make achievement-precluding (or devaluing) interventions today to allow for more potential achievements in the future.

The second concern is that this line of thought only justifies the use of a nudge when an achievement-preserving alternative is unavailable or ineffective enough to justify the loss of achievements in the short term for the potential of more later. More investigation is required for determining if achievement-preserving alternatives are available in all or most of these cases, so I will not comment on that here.

\section{Objection - Designing a nudge is an achievement}

A final objection is that designing and executing a nudge is an achievement, I have argued that achievements have value. So, it seems odd to argue against the use of nudging in an attempt to defend achievements. I will grant that this does seem peculiar. What the objection shows is that in evaluating the costs of nudging, we may need to consider the value generated from the achievement of nudging others. A nudge may diminish the value of the achievements of those nudged or preclude their actions' counting as achievements, but it may be an achievement nonetheless.

\footnotetext{
${ }^{78}$ I believe this is roughly the position Conley's takes in Against Autonomy (2012). I will discuss her view more in the next chapter.
} 
However, I do suspect that advocates of nudging will not be able to use this line of reasoning to defend specific nudges that they often use as examples. The examples often try to show that nudging requires very little effort to implement and yet can have large impacts on behavior. This means that executing a nudge may not meet our difficulty condition. Further, it is not clear that enough sustained effort is required for designing and executing a nudge to push the effort required to nudge above the required threshold. And even if the condition is met, the achievement may be of little value when compared to the value of the achievements nudgees would have made free from the influence of the nudge.

\section{Objection - Implausibly few achievements}

One might object that the account of achievements that I have used here implies that there are implausibly few achievements. Framing, defaults, and other unconscious influencers impact our activities if the choice architecture is intentionally designed or not. So, the objection goes, the concerns I have raised about the impact of nudges on achievements should also apply to these undesigned influences. And, if the impact of framing, defaults, and the like is as pervasive as behavioral economists and psychologists make it out to be, then we should be worried that these influencers often preclude our achieving things or often render our achievements less valuable. We should be concerned that the argument I have advanced implies that there are very few achievements, fewer than we intuitively believe there to be. So, the objector may conclude, the argument I 
have given should be rejected because it implies that there are counterintuitively few achievements. $^{79}$

It may be true that the argument I advance here does imply that there are fewer achievements than we generally assume. However, it is not clear that it implies that there are implausibly fewer achievements. I think the objection points to something correct, but misses something important.

What the objection gets correct is that on my account good luck can preclude something's being an achievement or diminish the value of the achievement. And, agents may be lucky that the choice architecture unintentionally activates certain biases that reduces difficulty or the need for competent causation, which can threaten the status of something's being an achievement or diminish its value as an achievement. However, it is not a mistake to say that the influence of luck should have some role in determining how valuable something is as an achievement and if it is an achievement at all. Therefore, it is not a mistake to think that in some cases, something will be precluded from being an achievement or be less valuable as an achievement because some bias was activated.

What the objection misses is that when faced with choice architecture that activates biases unintentionally, it is unlikely that cognitive biases only reduce difficulty or hinder competent causation. When agents are faced with such architecture, it is possible that counterbalancing biases are activated, and therefore there is a negligible effect on achievements. Or, it might be that some choice architecture unintentionally increases difficulty or promotes competent causation. If it increases difficulty, then one faces the bad luck of having to overcome this increased difficulty to accomplish the

\footnotetext{
${ }^{79}$ I thank the audience from the Great Plains Philosophy Symposium for raising this objection.
} 
action. In which case, it may now be an achievement or more valuable as an achievement. If it increases competent causation, then that may render the action an achievement or increase its value as an achievement. So such choice architecture can contribute to their being more achievements and more valuable achievements.

My assumption is that across a large sample, these effects will largely cancel each other out as it applies to such choice architecture. However, when one nudges another, this balance is upset. It would be like loading dice such that there is an increase in the instances of good luck over bad. Choice architects would increase the instances in which choosers are faced with less difficulty or less of a need to competently cause results. In this way, there can be fewer achievements when choosers are nudged. And, this can be true without their having to be implausibly few achievements when choosers are not nudged. 


\section{Chapter 4: Does Nudging Provide Reasons?}

Thus far, I have presented two arguments that there is something problematic about the use of nudges. In this chapter, I consider a possible response to these concerns. The response might go something like this: nudging is sometimes fine because it helps choosers appreciate the reasons they have for acting. This seems to be the view that Jason Hanna advances. Something about a nudge's ability to help one appreciate reasons undercuts whatever prima facie wrongness nudging may seem to have.

There are appropriate concerns one may have with this line of reasoning. After all, it does not seem plausible that one can do anything so long as it provides or helps one to appreciate reasons. For example, I cannot hold a gun to your head in an effort to get you to do what you have reason to do. But, it seems plausible that I may do some mild actions and nudging may count as a such a mild action. So, there may need to be some refinement as to how and when one may nudge to help a chooser to appreciate reasons, but the view seems plausible enough.

In this chapter, I will briefly explore Hanna's position. I will raise an objection that may best be described as "shallow" in that it challenges that nudges are permissible ways to get one to appreciate reasons. However, the bulk of this chapter will focus on a "deeper" objection: that we either do not have reason to do what we can be nudged into doing, so there is no reason to appreciate, or the nudge would be unnecessary for helping one to appreciate his or her reasons, so its role in the appreciation of reasons cannot undercut the prima facie wrongness of nudging.

To make this argument, I will adopt Kate Manne's account of reasons and augment it with George Tsai's work on rational persuasion. 


\section{What is it to appreciate reasons?}

Jason Hanna says that there are many ways to fail to appreciate the reasons that facts provide. To use his example, we can imagine someone who strongly wants to live a long life "and desires to be active into old age". ${ }^{80}$ When such a person considers smoking, "she may fail to apply the risks appropriately to her own case, she may ignore the risks or try not to think much about them, and she may fail to vividly imagine the severity of the risked outcomes". ${ }^{81}$ In these ways, she may fail to appreciate the reasons she has not to smoke. That is, she fails to assign the reasons she has not to smoke their appropriate weight when she deliberates.

Hanna recognizes that there is disagreement on what counts as the appropriate weight to assign to a reason. Some will hold that it is objective and others will say that it depends on "the agent's own goals, desires, and values". ${ }^{82}$ Hanna does not take a position one way or the other, but for the purposes of this chapter I will assume that the appropriate weight to assign to a reason depends on the agent's goals, desires, and values. I will do so for two reasons. First, I personally find such an account more plausible. Second, it better aligns with the commitments of libertarian paternalists. Thaler and Sunstein claim that they are trying to "make choosers better off, as judged by themselves". ${ }^{83}$ Presumably this indexing to the individual regarding welfare should also apply to how to weigh the reasons one has such that different persons can have different judgments regarding similar circumstances.

\footnotetext{
${ }^{80}$ Hanna (2015, p. 628).

${ }^{81}$ Hanna (2015, p. 627).

${ }^{82}$ Hanna (2015, p. 628).

83 Thaler and Sunstein $(2009$, p. 5) [emphasis in the original].
} 
Hanna holds that some nudges are unobjectionably manipulative because they help us to appreciate reasons. In our smoker example, ${ }^{84}$ because smoking can undermine her ability to live a long and active life, she plausibly has a reason not to smoke. If she fails to appropriately weigh the risk of missing out on a long and healthy life given that she smokes, then she fails to appreciate the reasons she has not to smoke. And, if some suitably structured nudge were to help her to refrain from smoking by exploiting a bias to cause her to adjust her calculation of what the downsides of smoking are, then she has been nudged in a way that allows her to appreciate the reasons she has not to smoke. And, according to Hanna, this manipulation is unobjectionable in virtue of the fact that it helps her to appropriately appreciate these reasons.

\section{A shallow reason for rejecting this account}

One reason for rejecting this account is that once the example is altered to better reflect how nudging would actually function, it is no longer clear that the prima facie wrongness of nudging is undercut. To demonstrate this, I first want to show that there is a flaw in the intuitively permissible smoking example and then show that in an example without this flaw it is not obvious that nudging is permissible.

The smoking example seems plausible because our smoker has previously existing preferences. She has a strong preference for living a long and active life and it is assumed she has a weak preference for smoking. With knowledge of these preferences in hand, we are then able to deduce that she has inappropriately weighed the risks of

\footnotetext{
${ }^{84}$ The example only stipulates that the individual is considering smoking. However, it is easier to simply refer to this individual as "smoker". Nothing about the analysis should hang on if the person considering smoking actually smokes.
} 
smoking if she smokes. However, as was noted in a previous chapter, the existence of cognitive biases that make nudging possible are thought to be evidence that choosers lack well-formed preferences. So, if she can be nudged to not smoke, then we have evidence that she does not have a well-formed preference for either smoking or not smoking. Or, it is not clear how strong the preference she has for smoking is. So, it cannot be concluded whether she has weighed the risks of smoking appropriately. Perhaps she has not appropriately appreciated the risks, but it is not clear that this can be known by a choice architect. ${ }^{85}$ In the absence of such knowledge, it seems impermissible to manipulate her just because it might help her to appropriately appreciate reasons if she did in fact inappropriately appreciate them. The prima facie wrongness does not seem to have been undercut.

Once we remove the stipulation of what the smoker's preference are, it seems less intuitive that the justification for saying that the manipulation is unobjectionable still applies. Further, it seems that choice architects generally will not know what the preexisting preferences of choosers are. So, the case where the stipulation of the preferences is removed is more realistic, which adds to the strength of the shallow objection. However, even if this argument is unpersuasive, there is a deeper objection to consider.

\section{The deeper objection}

\footnotetext{
${ }^{85}$ I can imagine a case where an individual approaches a choice architect for help, discusses his or her goals and preferences, and the choice architect designs a personalized nudge at the request of the chooser.

However, in this case, the prima facie wrongness is not undercut by the role the nudge plays in helping the chooser appreciate his or her reasons but by the consent given by the chooser to be nudged. I return to this issue in the final chapter.
} 
The deeper objection to the idea that nudges can be unobjectionably manipulative when they help a chooser to appreciate reasons is that choosers either do not have reason to do what they can be nudged into doing or the nudge is causally redundant. In which case, either there is no reason to appreciate or the nudge is unnecessary in the appreciation of reasons and its role cannot be cited as justification of its use. This is understandably a counter-intuitive claim. After all, it seems that our smoker should have some reason for not smoking. However, I will use a plausible account of reasons to show that the smoker does not have a reason not to smoke or if she does, the nudge does not help her appreciate that reason.

To build this account, I will fuse some of the work of Kate Manne with some of the work of George Tsai. Manne's own account of reasons draws heavily from reflection on our conversational practices and the work of P. F. Strawson. The insight is that when we engage with another person, the way we do so can be placed on a continuum between two extremes. We can treat the other person as an equal or we can treat him or her as an object. For example, imagine that we are having a conversation where we are trying to decide where to go to dinner. At one extreme as to how our conversation can go, you and I may both make suggestions and negotiate on where to eat and each of us views the interests and opinions of the other as deserving equal consideration. At the other extreme, you may refuse to hear any suggestion I make and physically take me against my will to your favorite restaurant.

These two extremes map onto what Strawson calls the "interpersonal mode" and the "objective mode" of viewing or treating others. When we engage with another in the interpersonal mode, "we view them and treat them as a human being much like ourselves. 
[...] For one thing, we regard them as a sovereign creature — or, roughly and less fancily, as both equipped and entitled to make their own decisions". ${ }^{86}$ However, while in the objective mode, we view and treat the other "as a kind of human object to be managed, cured, or navigated around". 87

Of course, many of our interactions may not lie clearly at either of these extremes. Manne recognizes as much in a footnote where she says that "[m]ost of human life is lived in the complicated middle". ${ }^{88}$ I too recognize that our actual interactions may not cleanly fit into these two categories, but, I will proceed as though these categories are exclusive and exhaustive. What is going to matter is that nudging is a way of engaging with the nudgee in the objective mode and not the interpersonal mode.

The bearing that this distinction has on an account of reasons is that "it is only insofar as one adopts the interpersonal stance towards someone that it is possible to reason or argue with them [sic], or offer them collaborative advice or friendly suggestions about what they ought to do" ${ }^{89}$ As one can only reason with another in the interpersonal mode, one can only give a reason while in the interpersonal mode. Evidence for this comes from reflection on our conversational practices. A counterexample would have to show that I reason with someone while treating him or her in the objective mode. But, if I were to interact with another in the objective mode, I would not be trying to get the individual to exercise his or her agency. Instead, when in the objective mode, I may be trying to undermine or simply ignore the other's agency. In the objective mode I can manipulate, threaten, physically restrain, coerce, or make demands. However, in none of

\footnotetext{
${ }^{86}$ Manne (2014, p. 95).

${ }^{87}$ Manne (2014, p. 95).

${ }^{88}$ Manne (2014, p. 96).

${ }^{89}$ Manne (2014, p. 96).
} 
these instances would one say that I am reasoning with the other person. There does not seem to be a case in which one treats another as an object but still reasons with him or her.

With this distinction in hand, I can now present Manne's definition of a reason. A reason for A to $\varphi$ is “a consideration which would be apt to be cited in favor of A's $\varphi$-ing, when we are reasoning with her about what she ought to do, as her ideal advisor who is doing her job as well as is possible". ${ }^{90}$ This definition needs some unpacking. Manne understands the considerations that are apt to be cited in favor of A's $\varphi$-ing as those which would (at least somewhat) motivate A to $\varphi \cdot{ }^{91}$ Further, the ideal advisor must interact with the advisee in the interpersonal mode.

Manne's account is attractive because it creates a close connection between our reasoning practices and what reasons we have and it eliminates the possibility of one's being alienated from his or her reasons. Because the reason must be capable of motivating you to do the action it gives you reason to do, it can properly be said to be your reason. ${ }^{92}$ However, it is not the case that merely anything that motivates counts as a reason. To illustrate this, consider the following example.

Compulsive Agreer: Jon is having difficulty getting one of his employees, Marc, to sign up for the company 401(k) plan. He firmly believes that it would be good for Marc to enroll. Jon happens to know that Marc has a quirk. He knows that if Marc is given a sheet of paper of a particularly hideous shade of blue, he will read what is on the paper and agree to whatever it says, no matter what. Lucky for Jon, he recently received a packet of paper in this shade. He prints the appropriate paperwork onto the paper and Marc is now signed up for the company 401(k) plan at the default savings rate.

\footnotetext{
90 (Manne 2014, p. 105).

91 (Manne 2014, p. 105).

${ }^{92}$ For an alternative account of reasons that rejects that a reason must be capable of motivating the agent, see Julia Markovits's Moral Reason (2014). Markovits argues that Robert Johnson's (1999) James Bond does have a reason to see a psychiatrist even though he cannot be motivated to do so. Markovits's account also uses an ideal advisor, but, the advisor is interestingly different than Manne's advisor.
} 
The fact that the agreement is printed on paper of a particular shade is not relevant to whether or not Marc should enroll. Rather, he agrees because "there is some weird feature of this man's psychology which is functioning arationally, much like the proverbial blow to the head". ${ }^{93}$ If what it takes to motivate him into enrolling is one's taking advantage of this quirk, then it seems that he does not have a reason to enroll. Further, by taking advantage of this quirk, Jon no longer seems to be reasoning with Marc but is treating him like an object that can be controlled or manipulated to produce a desired result.

Many nudges seem to work by taking advantage of arational aspects of nudgees' psychologies to produce some result. ${ }^{94}$ For example, a nudge that takes advantage of ordering effects, default bias, or inertia encourages certain behaviors by making some states that are irrelevant to the decision obtain. If Jon is not interacting with Marc in the interpersonal mode when he nudges him, by analogy, other nudgers are not interacting in the interpersonal mode with nudgees when they nudge by introducing irrelevant factors. So, they are not reasoning with the nudgees nor does the nudge provide them with reason to do some action.

Perhaps there is a breakdown of the analogy between Compulsive Agreer and some nudge cases. After all, some nudges operate by providing true and relevant information to the chooser. Such a case seems different from one where the nudge functions by introducing irrelevant factors. For example, a nudge might function by framing relevant information in a positive way. Manne's account makes it such that this

\footnotetext{
${ }^{93}$ Manne (2014, p. 104).

${ }^{94}$ As Conly puts it, "The point of the nudge is to push you in ways that bypass your reasoning. That is, they use your cognitive biases, like the tendency to go with the default option to bring about good results" (2012, p. 30).
} 
is still not enough for the nudge to give the agent a reason. The problem in both instances is that the nudge has a causal influence but not a rational one. The chooser's decision is not impacted by the normative significance of the information but by its mode of presentation. ${ }^{95}$

This distinction between causal and rational influences is important because there may be cases where a chooser is going to make a particular selection even if he or she is not nudged. This may be because he or she can be reasoned with or is simply set on making a particular choice. We can imagine such a case where the agent is nudged, and this causes him or her to make the selection he or she was always going to make. In such a case, there might be some reason for the agent to do the action, but the nudge is causally redundant in helping the agent appreciate that reason. In which case, its role in helping the agent to appreciate the reasons he or she has does not make it permissible to use the nudge. To illustrate this, I want to amend Compulsive Agreer. If Marc could have been talked into enrolling in the 401(k) plan without the use of the blue paper, or Marc was going to agree to enrolling anyways, then Jon seems unjustified in manipulating him. The consequences would have been the same, so the consequences cannot confer permissibility on Jon's use of the paper. But, that Jon treats Marc in the objective mode does seem to confer some prima facie wrongness. Some story would have to be told to explain how Jon has not failed in his duty to treat Marc as an end in himself but that story cannot include that it helped him to appreciate his reasons.

A dilemma emerges. Either the chooser was going to do whatever the nudge is designed to nudge him or her to do or could be talked into doing while in the

\footnotetext{
${ }^{95}$ I am drawing from Manne's discussion on p. 104 to justify this claim. My example is different than hers, but I believe that these differences do not change the interpretation of the case.
} 
interpersonal mode, or the chooser was going to do otherwise. If the former, then the use of the nudge as a means does not seem justified. Its role in helping one appreciate the reasons one has does not render its use permissible because it is causally redundant or a morally preferable means of motivating the chooser was available. If the latter, then one does not have a reason to do the action because one cannot be motivated to do it without leaving the interpersonal mode and using some arational means. Therefore, the use of a nudge in helping one to appreciate reasons either does not confer permissibility on nudging or one does not have reason to do what one is nudged into doing and therefore it cannot help one appreciate the reasons one has. Applied to our smoker example, this means that if she could not be motivated to not smoke without the influence of the nudge, then we have to accept that she does not have a reason to refrain from smoking. We would have to abandon the practice of reasoning with her to get her to not smoke. If she could be motivated without nudging her, then it seems difficult to explain how the nudge plays a role that undercuts the prima facie wrongness of using someone's psychological quirk to produce some result.

One may wonder why it is wrong to nudge someone into doing what they were going to do anyways or could be talked into doing without exercising arational influence. To explain why, I turn to George Tsai's account of rational persuasion as paternalism. Doing so will reveal some of the constraints on how the ideal advisor referenced in Manne's definition may not act.

What Tsai demonstrates in his paper is that one can be paternalistic while engaging in what looks like rational persuasion. Before presenting the elements I will be borrowing from his account, I need to make two preliminary points. First, he is focused 
on cases of interpersonal paternalism, such as cases between friends, and not cases of institutional paternalism, such as ones of a government and its citizens or a physician and his or her patient. However, he does believe that his account may generalize and I will be generalizing it here. ${ }^{96}$ Second, Tsai does not have the same constraints on what counts as a reason as Manne. He will often say that one is offering a reason when in fact one is not because one is no longer in the interpersonal mode. But, we can understand Tsai as helping to identify one way an ideal advisor can act impermissibly and therefore what would count as a failure to provide reasons on Manne's account.

An advisor can act paternalistically when engaging in what looks like the provision of reasons because "reasons provision can be motivated by and express distrust in someone's competence to canvass or weigh reasons, and can occlude an opportunity for someone to canvass or weigh reasons herself". ${ }^{97}$ To borrow from Tsai's example, you may be trying to decide between attending graduate school for philosophy or law school. I may be worried that you will make a decision that is not in your interest. So, before you have time to engage in serious deliberation on the matter, I present lots of information to you about why law school is the better option for you. The information is all true. But, I have preempted your ability to make your own decision. Further, I am motivated by and implicitly expressed mistrust in your capacity to competently gather and weigh evidence. In this way, I have acted paternalistically, and, according to Tsai, I have acted prima facie wrongly.

\footnotetext{
96 Tsai $(2014$, p. 80$)$.

${ }^{97}$ Tsai $(2014$, p. 84).
} 
Tsai formalizes the conditions for these kinds of paternalistic acts in this way: "I propose that the following are at least jointly sufficient conditions for an action, $\mathrm{Y}$, to be prima facie wrong in the distinctive way paternalistic actions are:

(1) Y is motivated by distrust or lack of faith in the target's competence or capacity to advance or protect her own welfare through the exercise of her agency.

(2) Y conveys (sends the message, perhaps indirectly) that the target lacks the competence or capacity to advance or protect her welfare through the exercise of her agency.

(3) Y intervenes in (intrudes on, interferes with, takes over) the target's sphere of agency, limiting the target's legitimate exercise of her agency." ${ }^{\circ 8}$

While Tsai does say that he assumes that paternalism is prima facie wrong, this should be a safe assumption to make when considering the paternalistic acts he is interested in. ${ }^{99}$ Such acts seem disrespectful. They are motivated by and convey a negative assessment of the agent. Further, the act of intervening in the agent's sphere of agency, perhaps "occlude[ing] an opportunity for [the agent] to canvass or weigh reasons herself" is itself considered objectionable by some authors. ${ }^{100}$ Part of what explains this wrongness is that

\footnotetext{
${ }^{98}$ Tsai does distinguish between rational persuasion and rational manipulation. Many nudge cases seem to be instances of rational manipulation. However, the best case for a nudge's helping one to appreciate the reasons he or she has is if one can nudge while serving in the ideal advisor role that Manne imagines. So, I am assuming that nudges are instances of rational persuasion such that nudgers can serve this role (p. 88). ${ }^{99}$ Tsai $(2014$, p. 81).

${ }^{100}$ Tsai (2014, p. 84). Mark White (2013) is an example of such an author. He objects to the use of nudges because they substitute the will of the choice architect for the will of the chooser. In the example above, I substitute my evidence and reasoning in place of yours.
} 
"When the provision of reasons preempts the other person's own deliberative activities such that her decisions about important life questions cannot then be seen as flowing from the independent exercise of her capacities to canvass and weigh reasons, the result can be a form of loss in being unable to see herself as a self-directing agent realizing purposes of her own.". ${ }^{101}$ Finally, it does seem that when these conditions hold, the paternalizer is interacting with the paternalized in the objective mode, and doing so seems prima facie wrong.

What should be troubling for the advocates of nudging is that the use of nudges seems to satisfy the three conditions above. Their use is motivated by a belief that choosers make systematic errors in reasoning. This is a result of the heuristics and biases research that motivates the nudge project. A nudge conveys the message that choosers lack the competence or capacity to advance or protect their own welfare. Finally, the nudge intervenes in the chooser's sphere of agency. This is precisely what Cohen sees as being the role that nudges can play in medicine. He believes that nudges can be used to influence patients into forming preferences that lead to their consenting to their physician's medical recommendation. Without nudges playing this preemptive role, patients may form preferences contrary to the physician's recommendation, thereby creating a tension between the physician's duty of beneficence and duty to respect patient autonomy. Thus, nudgers act in this paternalistic and (on the account I advance here) prima facie wrong way. They do not behave like ideal advisors interacting with choosers in the interpersonal mode. So, they cannot be providing reasons nor justifiably helping agents to appreciate reasons.

101 Tsai (2014, p. 79). 
In her criticism of nudging, Conley denies that this kind of paternalism is morally

wrong, but she does reach a similar conclusion about its being manipulative. What is striking about her description is that it supports that nudgers satisfy Tsai's three conditions. As she puts it:

First, Libertarian Paternalism is manipulative. That is, it does not suggest that we engage in free and open discussion in order to rationally persuade you to change your ways. Sunstein and Thaler are not opposed to free and open discussion, but they don't think engaging you in rational argument is enough to get you to choose efficiently, because of the cognitive deficits they have described. The point of the nudge is to push you in ways that bypass your reasoning. That is, they use your cognitive biases, like the tendency to go with the default option to bring about good effects. There is a sense in which they then fail to respect people's decision-making ability. The assumption is that because our decision-making ability is limited we need to use arational means to seduce people into doing what is good for them, and are trying to get people to act through the use of arational means. It is true that for libertarian paternalism all options remain open, which means that some people could, in fact, resist this arational persuasion and rely on their own cognitive abilities to decide what they want to do. The assumption is, though, that most people won't do this but instead will fall in the direction in which they are nudged.

I don't think this is morally wrong, since I agree that we need to help people get where they really want to go. However, insofar as it is supposed to render the position more palatable to the classic liberal, it fails. Rather than regarding people as generally capable of making good choices, we outmaneuver them by appealing to their irrationality, just in more fruitful ways. ${ }^{102}$

What might speak in favor of nudging is that the judgments about the capacities of choosers may be true. However, all I am considering here is the defense of nudging on the grounds that it helps choosers to appreciate reasons. So, one cannot object to my argument by conceding that nudgers do interact with nudgees in the objective mode. ${ }^{103}$ Even if nudgers have true judgments about the capacities of choosers, and even if the fact

\footnotetext{
${ }^{102}$ Conley (2012, p. 30).

${ }^{103}$ I will consider an objection that it is permissible for nudgers to interact with nudgees in the objective mode, but the objection will be considered without the commitment to nudges' helping one to appreciate reasons.
} 
that these judgements are true undercuts the wrongness of acting paternalistically in this way, I will still have shown that defending the use of nudges by appealing to their ability to help choosers appreciate reasons is the wrong ground to defend from.

\section{Objection - Too few reasons}

The first objection that I will consider is that Manne's account is implausible because it implies that we have far fewer reasons than we generally believe that we have. It seems that we are often subject to the effects of cognitive biases. The insight of the heuristics and biases literature is that our behavior is often shaped by arational factors, which on Manne's account, would mean that we are often behaving as though we have suffered a "proverbial blow to the head". ${ }^{104}$ When we are motivated to do an action because of such a blow, we do not have reason to do that thing on Manne's account. Thus, it seems that we must not often have reason to do what we believe we have reason to do because we are often influenced by arational factors as a result of our cognitive biases.

I am going to reply to this objection in three ways. The objection takes the form of a modus tollens:

If Manne's account is correct, then we have very few reasons.

We do not have very few reasons.

Therefore, Manne's account is not correct.

My first reply to the objection is to challenge the second premise. It does seem to be an expected result of Manne's account that we have fewer reasons than we might think that we have. This is in part a result of her account's being an internalist account. As evidence

${ }^{104}$ Manne (2014, p. 104). 
that this result is expected, consider her example of the man who cannot be motivated to stop being nasty to his wife. It seems to us that he does have a reason to stop this behavior, it is immoral for him to continue behaving this way. But, on Manne's account, he does not have such a reason because one could not motivate him while reasoning with him. This is an expected result of the account and seems to explain Manne's title "Internalism about reasons, sad but true". ${ }^{105}$

But, advocates of nudging who endorse the heuristics and biases approach should endorse that we have very few reasons for our actions given how often we are influenced by these biases and that we do not have reason to do what our biases motivate us to do. If we rarely act as a result of the biases that motivate the nudge project, then the potential influence that nudging would have over choosers would be low. But, Sunstein and Thaler claim that nudging is inevitable, seemingly implying that our actions are often influenced by our biases and that nudging has great potential for "Improving Decisions About Health, Wealth, and Happiness". ${ }^{106}$

Further, it would be odd for advocates of nudging to claim that the second premise is true. Consider the following three claims, which I think a nudge advocate who endorses the heuristics and biases approach yet wishes to assert that we often have reasons would have to endorse:

We are often influenced by our biases. Nudges incline us to act contrary to how our biases incline us to act. We have reason to act as our biases incline us to act.

One's endorsing these three claims implies something odd, that a nudge inclines people to act contrary to their reasons. It does seem like we may have prudential reasons for

\footnotetext{
105 Manne's analysis of the example can be found on pages 112-116.

106 This is the subtitle of their 2009 book, Nudge.
} 
encouraging people to act contrary to their reasons. But, I do not think it could be claimed that one can cause another to act contrary to his or her reasons while also trying "to steer people's choices in directions that will improve their lives". ${ }^{107}$ That is, one cannot nudge another to act contrary to his or her reasons while also maintaining the standards of libertarian paternalism. To endorse those three claims, a nudge advocate would seemingly need to abandon a key aspect of the broader nudge project, libertarian paternalism.

A possible way of responding is to note that nudges work by employing the cognitive biases of choosers. So, choosers do, at least sometimes, have reason to do what they are inclined by their biases to do. Specifically, they have a reason in those cases where their biases inclined them as the result of a choice architect's nudging them. I think this produces some odd results, but what is most relevant here is that it fails to show that the second premise is true. It is not clear that choice architects intentionally nudge us very often. Thus, it would seem that we do have very few reasons. So, advocates of nudging seemingly cannot endorse the second premise and therefore cannot help themselves to this objection.

The second way of responding to the objection is to convert the modus tollens into a modus ponens. Rather than focusing on whether or not we have very few reasons, we should focus on whether or not Manne's account of reasons is correct. I believe that it is. Unlike other accounts, it prevents agents from being alienated from their reasons. It plausibly ties our reasoning practices to the reasons that agents have. And, it correctly

\footnotetext{
107 Thaler and Sunstein (2009, p. 5).
} 
captures the intuition that that one does not have a reason when acting arationally, which is supported by the Compulsive Agreer case.

The final way of responding to the too few reasons objection is to reject the first premise. It might be that if Manne's account is correct, we should count fewer reasons than many other accounts. However, this does not imply that we have to agree that we have very few reasons. Unfortunately, I do not believe that advocates of nudging can help themselves to this reply to the objection. This weakens the persuasiveness of the response substantially, however, I will present it anyway.

One can reject the first premise by rejecting the heuristics and biases research program. If cases where our supposed biases cause us to stay with default options, be sensitive to framing, etc. were instead instances of information leakage, implicit endorsement, or something similar, then we may have reason to do what our biases incline us to do. If a physician frames information in a certain way and this is automatically received as an implicit endorsement of a course of action, then the patient is being rationally influenced to take that action. On Manne's account, the physician in this case is acting as an advisor and motivating the patient to act by rationally influencing the patient. Thus, Manne's account can endorse that the patient has a reason as a result of the framing used. Similar explanations for how we have reason to do what our biases incline us to do may be available. This would allow one to reject the first premise, as well as the second. Further, in doing so, one still does not have to accept that Marc has a reason in Compulsive Agreer as he seems to be only causally and not rationally influenced to enroll. 


\section{Objection - Permissible to treat people in the objective mode}

A second way of objecting is to abandon the view that nudges help one to appreciate reasons but instead argue that there are times when it is permissible to treat another in the objective mode. In such scenarios, nudging would not help one to appreciate his or her reasons but would seem unproblematic.

I will admit that there are times when it is fine to treat another in the objective mode. However, these are generally when that other is impaired in some way. ${ }^{108} \mathrm{We}$ generally should engage with others with a presumption of competence. ${ }^{109}$ When a choice architecture is designed to engage individuals in the objective mode, this presumption of competence is violated. This seems morally problematic because it will likely treat agents who should be presumed to have autonomy as though they do not have autonomy. So, it would be generally problematic to nudge choosers.

I do not deny that there are cases where it can be presumed that anyone affected by a given nudge is not competent. However, these would be special cases where there is something special about the choosers in that specific environment. For example, a choice architect designing an elementary school cafeteria does not have to have a presumption that the school children are competent agents. But again, these will be special cases where there is good reason to ignore the general requirement to extend to others a presumption of competence.

\footnotetext{
108 Manne (p. 95) explores when we may "retreat" to the objective mode. ("Retreat" is Strawson's characterization.)

${ }^{109}$ Further, because client autonomy is generally highly valued in professional ethics, it is generally true that we should extend to others a presumption of competence even when engaging with them as professionals, and we should not engage with clients in the objective mode.
} 
One way advocates of the use of nudges might respond is to claim that the discovery of the cognitive biases that motivate the use of nudges gives good evidence that individuals should not be presumed to be competent and therefore may permissibly be generally engaged in the objective mode. I will grant that this is a position that one could take. However, it is a position that would require a rigorous defense. It would have to be explained why our practices and intuitions do not indicate that we are generally incompetent. It would have to be explained why nudgers are supposed to try to "make choosers better off, as judged by themselves". ${ }^{110}$ If choosers do not have to be presumed to be competent, then their judgments seem irrelevant. Most importantly, it would have to be explained why nudging should be preferred over hard paternalism. After all, nudging allows those with the strongest motivations or "who have stronger and crazier convictions than the norm" to act contrary to the nudge even if it is irrational for them to do so. ${ }^{111}$ The use of nudges was supposed to be favorable over hard paternalist interventions because nudges supposedly respect autonomy. But, if our biases prevent us from being competent, and we therefore lack autonomy, then it isn't clear why one shouldn't try to guarantee good results by favoring hard paternalism.

I am not claiming that these and other difficulties cannot be overcome. However, I do not believe that they all can.

\footnotetext{
110 Thaler and Sunstein (2009, p. 5).

111 Conly (2012, p. 31-32).
} 


\section{Chapter 5: What to Make of Behavioral Insights}

What is to be made of the potential that the use of nudges is supposed to present us? Nudges have been promised as ways of improving people's lives, but I have argued that it may be impermissible to use this tool. My conclusion here is that, in general, this potential cannot be permissibly tapped. Even when one of the considerations against nudging does not apply, others likely do. As an example, consider nudges that satisfy William Glod's Neutral Nudge Principle. As noted at the end of Chapter 2, nudges that satisfy this principle restrict the aim of choice architects to "(non-deceptively) manipulate one in order to bring one's actions back into alignment with one's own preferences or values, inasmuch as one has well defined preferences or values". ${ }^{112}$ Choice architects bound to this principle lack the capacity to interfere arbitrarily since they would have to track the preferences of individual choosers. However, the nudges created by such architects still likely express distrust in the ability of the nudgee to be reasoned with. The choice architect does not extend the nudgee the presumption of competence that agents are due and the architect intervenes in the problematic way that fits Tsai's schema. ${ }^{113}$

Further, as I have noted before, if securing the potential consequences of nudging is important, then it is difficult to see why one would not take Conley's position that the use of nudges is a poor half-measure. If improving the health, wealth, and happiness of people is important, then there is a strong case that one should engage in hard paternalism. After all, nudging an individual does not guarantee that the individual will

\footnotetext{
112 William Glod (2015, p. 605-606).

${ }^{113}$ When a nudge is designed with a particular nudgee in mind such that his or her preferences are being tracked and promoted it seems more likely that the nudge carries a message of distrust than if the nudge is designed to influence broad swaths of a population. In the latter case, it seems more likely that there is not mistrust of a particular agent but of agents generally. However, this would still be a case where individual agents are not being extended a presumption of competence.
} 
make the same choices as the homo economicus version of him or herself. An individual can still have very strong but misguided motivations and therefore not be susceptible to nudging. In such a case, the nudge will have failed to help improve the health, wealth, or happiness of the agent even though he or she seems to be the type of individual nudges are supposed to help. ${ }^{114}$

While the primary motivation for the use of nudges seems to be the realization of this promised potential, another motivation seems to stem from the heuristics and biases approach that nudge advocates endorse. The way that people make decisions is viewed as being flawed. As a result, there seems to be a lack of respect for the motivations people have and the choices that they reach when these choices may be the result of their cognitive biases. For example, I may come to desire having chocolate cake because it is prominently displayed at the front of the cafeteria and thereby come to choose to have chocolate cake. I can grant that I come to desire and choose to have cake as a result of the cognitive biases described by the heuristics and biases research program. However, this does not mean that my desire and choice are unimportant nor that it would be permissible to influence my motivation or choice. It may seem reasonable to believe that, since if the cake had not been placed there I would not have chosen to have cake nor formed the desire for cake, that the desire for cake is unimportant and the cake can, as part of a nudge, permissibly be moved where I will not form this desire nor choose to have cake. However, as Hayek notes, such an argument faces serious problems. ${ }^{115}$

\footnotetext{
${ }^{114}$ While it is possible that hard paternalism violates some side constraint and is therefore an impermissible means to achieve these ends when compared to using nudges, I will not consider this possibility here. Here I am only considering what follows if the promised potential consequences of using nudges are the thing that justify their use. I actually believe that nudging may be a less permissible means for achieving these ends when compared to hard paternalism, but I will not explore that here.

${ }^{115}$ Hayek (1961).
} 
The argument in favor of moving the chocolate cake because of how my desire for it arises is the same kind of argument that Hayek finds in Galbraith's chapter on the "Dependence Effect". Hayek puts it thusly,

The argument of this chapter [from Galbraith] starts from the assertion that a great part of the wants which are still unsatisfied in modern society are not wants which would be experienced spontaneously by the individual if left to himself, but are wants which are created by the process by which they are satisfied. It is then represented as self-evident that for this reason such wants cannot be urgent or important. This crucial conclusion appears to be a complete non sequitur and it would seem that with it the whole argument of the book collapses. ${ }^{116}$

The same argument applies to the cake example, as does the criticism. It can be granted that my desire for the chocolate cake is the result of the structure of my environment. This desire is not something I would have spontaneously experienced if the process that created this desire in me hadn't provided the means to satisfy it. But, it is not clear that this makes my desire for the cake unimportant nor that it would be permissible to ignore such desires or to question the choices made on the basis of these desires. The same is true of other desires that I might form (and the choices I make as a result of those desires) as a result of the environment I find myself in.

It is too great a leap for the advocates of the use of nudges to go from the finding that people have biases to the view that the choices made on the basis of these biases are unimportant and therefore can be permissibly interfered with. The fact that people make certain decisions about savings, diet, etc. as a result of anchoring, defaults, and other biases does not itself justify intervention. The fact that people have biases is insufficient to motivate the nudge project and insufficient to overcome moral objections to nudging.

${ }^{116}$ Hayek (1961, p. 346). 
So if using nudges is not justified because of the unimportance of these choices and desires nor because of the potential positive consequences, it is difficult to see what the case for the use of nudges could be. Given the concerns about domination, the loss of achievements or the value of achievements, and the treatment of agents in the objective mode, it seems that a useful heuristic is to have a presumption against the use of nudges.

\section{Overcoming the Presumption Against the Use of Nudges}

In chapter 3, I considered the objection that designing a nudge is an achievement; and I noted that it seems odd for me to argue against the use of nudges in an attempt to defend achievements. As part of my response to this objection, I noted that using nudges is generally presented as a low-effort way to produce desired results, and thus, it seems unlikely that implementing a nudge would count as an achievement, and even if it did, it would be unlikely that it would be a particularly valuable one when compared to the value of achievements nudgees would have made absent any nudge. But, in my discussion of that objection, I focused on one's nudging someone else. I did not consider what may follow if one nudged him or herself. The possibility that one could nudge him or herself presents an obvious way of overcoming the presumption against the use of nudges. Relatedly, this presumption would also be overcome if an agent has volunteered to be put in an environment where it would be reasonable for him or her to assume that he or she is going to be nudged. I will explore these two options below.

First, I wish to look at self-nudges. I will understand these as instances where one tries to develop choice architecture to influence his or her own choices by utilizing the fact that he or she has cognitive biases. For example, in an effort to eat healthier, I may 
rearrange my kitchen such that healthier foods are prominently displayed and easier to access.

Thaler and Sunstein seem to accept that self-nudging is possible given their discussion of stickK.com. ${ }^{117}$ As they describe it, this is a site where one can set a certain goal, specify how it is to be determined if that goal has been reached, and specify a penalty for failure to meet that goal. ${ }^{118}$ Of course this produces an incentive for the individual to reach his or her goal, but it also produces the effect of feeling committed to a particular end. So, the degree of influence of having made the commitment may be larger than the influence of just the financial incentive alone. If this is the case, then one can nudge oneself by using the site as one would be influencing oneself without significantly altering the incentives and by leveraging one's cognitive biases.

There may be some reason for thinking that self-nudging is still morally troubling. If one is not numerically identical with one's future self, then designing a choice architecture to nudge your future self would mean that one is actually nudging another person. However, such a view relies on counterintuitive metaphysical assumptions about personal identity. Further, such a view of personal identity would also render promise making impermissible. On this view, when you make a promise today, some other future person would be held responsible for it. Except under special circumstances that are not relevant here, one cannot permissibly make promises on behalf of another. But, we do generally believe promise making is permissible. So long as it is permissible for a person to engage in promise making, it is permissible for him or her to engage in self-nudging. Both are ways of influencing how one will act in the future and there seems to be no

\footnotetext{
${ }^{117}$ Here I use the capitalization that stickK uses on their website. Thaler and Sunstein use "Stickk.com".

118 Thaler and Sunstein (2009, p. 233-234).
} 
relevant moral distinction between the two to support saying that an individual may do the former but not the latter. ${ }^{119}$ In the absence of any reason to believe that one cannot permissibly nudge oneself, self-nudging seems to be immune to the presumption against nudging.

Other than nudging oneself, volunteering to be nudged also seems unproblematic. What will be difficult to assess is how explicit consent must be, but I believe that it does not have to explicit in all cases. There are circumstances where one should expect to be nudged when in those circumstances and nudging in these special narrow circumstances is unproblematic. For example, if one were to go to a weight loss camp, one should expect the camp organizers to use a mixture of bans, mandates, and nudges. But, it would be permissible for the organizers to use these given that campers have consented to their use by attending and remaining at the camp.

Of course, there may be other ways that the presumption against the use of nudges can be overcome. However, these two methods, self-nudging and volunteering to be nudged, seem to be the clearest ways.

\section{Lessons to Be Learned}

While I believe that there should generally be a presumption against the use of nudges, this does not imply that there are not important lessons to be learned from the heuristics

\footnotetext{
${ }^{119}$ Kantians may object that there is a way of making a morally relevant distinction. It may be that nudging yourself is akin to suicide or to selling oneself into slavery in that each is an instance of using yourself as a mere means. However, I simply disagree with the Kantians either that it is either possible to use yourself as a mere means, or if it is possible, that it is impermissible to do so. To paraphrase Mill from On Liberty, over oneself, one is sovereign.
} 
and biases literature at its foundation. I will briefly mention some possible lessons to be learned in medicine and in the field of combatting terrorism.

Cases like Medical Procedure from chapter 1 help to show that physicians can exercise influence over their patients even without meaning to. The fact that this is possible is an important lesson to learn. However, one does not have to conclude from it that doctors should exercise this influence. Rather, one could take from this lesson that one should take measures to mitigate or eliminate this influence.

One way to mitigate this influence would be to alter what Benjamin Freedman refers to as "offering truth". ${ }^{120}$ What happens when truth is offered is a physician attempts to find out how much a patient knows about his or her condition and how much he or she would like to know about his or her diagnosis and prognosis. Further, the physician tries to ascertain at what level of detail the patient would like this information. Freedman sees this as a way of respecting a patient's right to know important medical information without acting as though the patient has a duty to know this information. After all, the patient may not want to know about his or her diagnosis and may want family members to make relevant treatment decisions.

My suggested alteration is that in the process of offering truth to patients, physicians can explain to patients that the way information is presented can have an influence over patient behavior. I am not sure how this can best be done but here are two possible ways as applied to Medical Procedure. First, the physician could explain that risks can be presented in terms of what percent of patients are still alive five years after having some procedure or what percent are dead five years after. Then the physician

\footnotetext{
${ }^{120}$ Freedman (1993).
} 
could explain what impact each of these ways of wording risks has on patients and ask the patient if he or she wants to be given the risks of relevant procedures presented in terms of how many patients are alive after five years or how many are dead after five years. Alternatively, the physician could explain that the way risks are presented could influence the patient's decision and ask if he or she would like to know how these wordings may influence his or her decision, if he or she simply wants the risks presented in a certain way without knowing what influence it may have, or if the patient wants to defer to the doctor for deciding how to word the relevant risks. In this last case, the patient has volunteered to be nudged if the doctor decides to nudge the patient in a particular direction. However, this act of consenting removes the presumption against nudging in such cases.

Presumably, similar conversations could be had regarding the presentation of information in natural frequencies or percentages. If such an approach were tried, it could be explored if patients' being aware of these possible influences minimizes their effects. My suspicion would be no, however, it may be possible that taking this approach in some way debiases patients.

A second way of applying the lessons learned from the heuristics and biases literature is to use it as an argument in favor of what Veatch calls "deep value pairing". What I am suggesting here does not eliminate the influence of framing and defaults, but reduces the level of domination between physicians and patients. Under a system of deep value pairing, it is less likely that a gap will form between patient preference and medical recommendation, it is less likely that physicians could interfere, and physician interference would be constrained. If I am correct on these points, physicians would be 
able to provide patients the information they must inevitably provide without standing in a position of domination over those patients.

Deep value pairing is the idea that patients should see physicians who share their deep values. That is, they share similar "religious and political affiliations, philosophical and social inclinations, and other deeply penetrating worldviews". ${ }^{121}$ For example, patients who value maximizing their lifespans over virtually all else should be paired with physicians who share that value. While those who look to have as normal a life as possible (where they get to stay at home and maintain their usual routines), even if it means a shorter life, should be paired with doctors who show a large degree of concern for side effects that threaten a patient's ability to maintain his or her current routines. Veatch recognizes that these pairings will not eliminate biases, but because both parties share the same values, it is likely that physicians will recommend to their patients what the patients would have selected for themselves if they were "to become an authority in medical science". So, we can expect the gap between patient preference and medical recommendation to shrink or collapse entirely when there is deep value pairing.

If this gap collapses, then it seems less likely that physicians who are paired with patients who have the same deep values could interfere. Part of what generated the likelihood of physician interference was the inability of physicians to know a patient's valuation of non-medical goods that contribute to his or her wellbeing. It seems that if patients and doctors share the same values, then doctors will be far more successful in calculating how the patient would trade off medical and non-medical goods to maximize

${ }^{121}$ Veatch (1995). 
his or her wellbeing. Thus, the doctor is more likely to land on the optimal treatment to recommend to the patient.

Finally, since the doctor will know that he or she has been paired with a patient because of the values they share, the doctor will be constrained to trying to anticipate the patient's choice or constrained by the values they both share. So, a physician and patient who share a conservative approach to medicine that favors observation over intervention will not be free to frame risks to nudge a patient towards intervention. The physician would know that doing so violates both his or her and the patient's values. So, it seems that the capacity to arbitrary interference is removed or at least reduced.

A final lesson to be learned from the nudge literature is that, to combat the influence of cognitive biases, debiasing measures should be explored and shared. Lilienfeld, Ammirati, and Landfield note that our cognitive biases, such as confirmation bias, might be contributing factors "to ideological extremism and inter- and intragroup conflict". ${ }^{122}$ They believe that future work should be done to explore whether debiasing measures can be found, and if they can, if using them would reduce ideological extremism and inter- and intragroup conflict. What is important is that they do not advocate for the use of nudges to combat extremism, but for debiasing if it is possible to do so.

While I have argued that the use of nudges is morally problematic, I do not contend that there are no lessons to be learned from the literature that grounds the nudge project, instead, it gives us different directions to explore now that these biases are understood.

${ }^{122}$ Lilienfeld, Ammirati, and Landfield (2009, p. 391). 


\section{Bibliography}

Bradford, G. (2015). Achievement. OUP Oxford.

Bubb, R., \& Pildes, R. H. (2014). How behavioral economics trims its sails and why. Harvard Law Review 127(6), 1593-1679.

Cohen, S. (2013). Nudging and Informed Consent. The American Journal of Bioethics, 13(6), 3-11. https://doi.org/10.1080/15265161.2013.781704

Conly, S. (2012). Against Autonomy: Justifying coercive paternalism. Cambridge: Cambridge University Press, 2013.

Cowen, T. (2016, June 22). Conversations With Tyler. "A Conversation with Cass Sunstein on Judicial Minimalism, the Supreme Court, and Star Wars”. [Audio Podcast] Retrieved from https://medium.com/conversations-with-tyler/cass-sunsteinstar-wars-nudge-a7c874f3ce8c

Episode 732: "Bad Form, Wells Fargo" : Planet Money: NPR. (2016). Retrieved from http://www.npr.org/templates/transcript/transcript.php?storyId=499805238

Freakonomics. (2015, February 26). The Maddest Men of All Full Transcript. Retrieved from http://freakonomics.com/2015/02/26/the-maddest-men-of-all-full-transcript/

Freedman, B. (1993). Offering Truth: One Ethical Approach to the Uninformed Cancer Patient. Archives of Internal Medicine, 153(5), 572-576. https://doi.org/10.1001/archinte.1993.00410050012003

Glod, W. (2015). How Nudges Often Fail to Treat People According to Their Own Preferences: Social Theory and Practice, 41(4), 599-617. https://doi.org/10.5840/soctheorpract201541433 
Grüne-Yanoff, T. (2012). Old wine in new casks: libertarian paternalism still violates liberal principles. Social Choice and Welfare, 38(4), 635-645. https://doi.org/10.1007/s00355-011-0636-0

Grüne-Yanoff, T., \& Hertwig, R. (2016). Nudge Versus Boost: How Coherent are Policy and Theory? Minds and Machines, 26(1), 149-183. https://doi.org/10.1007/s11023015-9367-9

Hanna, J. (2015). Libertarian Paternalism, Manipulation, and the Shaping of Preferences. Social Theory and Practice, 41(4), 618-643. https://doi.org/10.2307/24575752

Hansen, P. G. (2016). The Definition of Nudge and Libertarian Paternalism: Does the Hand Fit the Glove? European Journal of Risk Regulation, 7(1), 155-174. https://doi.org/10.1017/S1867299X00005468

Hausman, D. M., \& Welch, B. (2010). Debate: To Nudge or Not to Nudge*. Journal of Political Philosophy, 18(1), 123-136. https://doi.org/10.1111/j.14679760.2009.00351.x

Hayek, F. (1961). The Non Sequitur of the "Dependence Effect". Southern Economic Journal, 27(4), 346-348. doi:10.2307/1055533

Hertwig, R., \& Ryall, M. D. (2016). Nudge vs. Boost: Agency Dynamics Under "Libertarian Paternalism" (SSRN Scholarly Paper No. ID 2711166). Rochester, NY: Social Science Research Network. Retrieved from https://papers.ssrn.com/abstract=2711166

Hough, A. (2016, August). Columbia police might soon need written consent to search cars. Retrieved from http://www.komu.com/news/columbia-police-might-soonneed-written-consent-to-search-cars/ 
Johnson, R. N. (1999). Internal Reasons and the Conditional Fallacy. The Philosophical Quarterly (1950-), 49(194), 53-71.

Lilienfeld, S. O., Ammirati, R., \& Landfield, K. (2009). Giving Debiasing Away: Can Psychological Research on Correcting Cognitive Errors Promote Human Welfare? Perspectives on Psychological Science, 4(4), 390-398. https://doi.org/10.1111/j.1745-6924.2009.01144.x

Lovett, F. (2001). Domination: A Preliminary Analysis. The Monist, 84(1), 98-112. Lovett, F. (2017). Republicanism. In E. N. Zalta (Ed.), The Stanford Encyclopedia of Philosophy (Spring 2017). Metaphysics Research Lab, Stanford University. Retrieved from https://plato.stanford.edu/archives/spr2017/entries/republicanism/

Manne, K. (2014). Internalism about reasons: sad but true? Philosophical Studies, 167(1), 89-117. https://doi.org/10.1007/s11098-013-0234-3

Markovits, J. (2014). Moral reason. Oxford : Oxford University Press, 2014.

[MizzouLaw] (2016, October 21). 2016 Earl F. Nelson Lecture: "Nudges That Fail" [Video File] Retrieved from https://www.youtube.com/watch?v=9Xi0ZPp0Hd8\&t=2390s

Nesterak, Max. "Nudging the UK: A Conversation with David Halpern." The Psych Report. Retrieved from http://thepsychreport.com/conversations/nudging-the-uk-aconversation-with-david-halpern/

Nozick, R. (2013). Anarchy, State, and Utopia. Basic Books.

Parliament. House of Lords (2011) Behavior Change. (HL 2010-2012 (179)). London: The Stationery Office.

Pettit, P. (1997). Republicanism: A Theory of Freedom and Government. OUP Oxford. 
Rizzo, M., \& Whitman, G. (2007). Paternalist slopes. NYU Journal of Law \& Liberty, 2(3), 411-443.

Selinger, E., \& Whyte, K. P. (2012). What Counts as a Nudge? The American Journal of Bioethics, 12(2), 11-12. https://doi.org/10.1080/15265161.2011.634485

Sher, S., \& McKenzie, C. R. M. (2006). Information leakage from logically equivalent frames. Cognition, 101(3), 467-494. https://doi.org/10.1016/j.cognition.2005.11.001

Sunstein, C. R. (2014). Why Nudge?: The Politics of Libertarian Paternalism (Reprint edition). New Haven: Yale University Press.

Sunstein, C. R. (2016a). Do People Like Nudges? (SSRN Scholarly Paper No. ID 2604084). Rochester, NY: Social Science Research Network. Retrieved from https://papers.ssrn.com/abstract=2604084

Sunstein, C. R. (2016b). People Prefer System 2 Nudges (Kind of), 66 Duke L.J. 121168.

Sunstein, C. R., \& Thaler, R. H. (2003). Libertarian Paternalism Is Not an Oxymoron. The University of Chicago Law Review, 70(4), 1159-1202. https://doi.org/10.2307/1600573

Thaler, R. H. (2016). Misbehaving: The Making of Behavioral Economics (1 edition). United States of America: W. W. Norton \& Company.

Thaler, R. H., \& Sunstein, C. R. (2009). Nudge: Improving Decisions About Health, Wealth, and Happiness (Revised \& Expanded edition). New York: Penguin Books. Tsai, G. (2014). Rational Persuasion as Paternalism. Philosophy \& Public Affairs, 42(1), 78-112. https://doi.org/10.1111/papa.12026 
Veatch, R. M. (1995). Abandoning Informed Consent. Hastings Center Report, 25(2), 512.

White, M. (2013). The Manipulation of Choice: Ethics and Libertarian Paternalism (2013 edition). New York, NY: Palgrave Macmillan. 


\section{Vita}

Paul Hamilton earned his B.A. in philosophy and political science from the University of Alabama in Huntsville in 2011. In 2012 he served as a research assistant for Dr. John Moser in Ashland, Ohio as a Koch Summer Fellow. He earned his M.A. in philosophy in 2014 and Ph.D. in 2018 at the University of Missouri. A series of unforeseen accidents have brought him to this point, it's unclear where they will take him next. 